Wirtschaftswissenschaftliche

Fakultät

October 2018

\title{
Toward an understanding of collaborative tax evasion: A natural field experiment with businesses
}

A publication of the Center of Business and Economics (WWZ), University of Basel.

(c) WWZ 2018 and the authors. Reproduction for other purposes than the personal use needs the permission of the authors.

Corresponding Author:

Dr. Annabelle Doerr

Mail: annabelle.doerr@unibas.ch 


\title{
Toward an understanding of collaborative tax evasion: A natural field experiment with businesses*
}

\author{
Annabelle Doerr ${ }^{\dagger \ddagger}$ Sarah Necker $\$$
}

\begin{abstract}
Sales from businesses to consumers provide fertile ground for collaborative tax evasion. However, little is known about the phenomenon. We conduct a natural field experiment with 2,900 businesses in which we take the role of consumers and vary if we request an invoice for the delivery of a service. We find that $56 \%$ of businesses approach consumers with the intention to evade. The fraction is zero in the regulated market and $72 \%$ in the unregulated market. It increases when consumers signal their willingness to collude. Consumers can save $25 \%$ of the legal price on average if they agree to evade.
\end{abstract}

Keywords: Collaborative tax evasion, evasion rent, field experiment JEL Codes: H26; C93; E26; J22; O17

${ }^{*}$ We gratefully acknowledge financial support by the Science Foundation of the University of Freiburg. This experiment was approved by the Ethics Committee of the University of Freiburg (EK-226/16). This study is registered in the AEA RCT Registry and the unique identifying number is: "AEARCTR-0003398. We are grateful for the support of all research assistants helping us to collect the data. We thank Lisa Bruttel, John List, Katharina Pfeil, Friedrich Schneider, and Conny Wunsch for invaluable comments. We thank participants of the following seminars and meetings for their comments: University of Chicago 2016/2018, University of St. Gallen 2016, CAFE Workshop 2016, University of Basel 2018, IMEBESS 2018, ESA 2018, EPCS 2018, IAB Colloquium 2018, Verein fr Socialpolitik 2018.

${ }^{\dagger}$ University of California, Berkeley, 549 Evans Hall, Berkeley, CA 94720-3880

${ }^{\ddagger}$ University of Basel, Peter-Merian Weg 6, 4002 Basel, Switzerland

$\S$ Walter-Eucken Institute, Goethestraße 10, 79100 Freiburg, Germany

๑University of Freiburg, Platz der alten Synagoge 1, 79098 Freiburg, Germany 


\section{Introduction}

When businesses sell goods or services to consumers, the incentives to report the transaction to tax authorities are often weak. Consumers usually do not benefit financially from asking for an invoice (Naritomi, 2016; Pomeranz, 2015). Rather, they may in fact receive a price discount when they agree to proceed without paper trail (e.g., Chang and Lai, 2004 European Commission, 2014). Although collaborative tax evasion implies that governments lose substantial amounts of tax revenue (Slemrod, 2007; Kleven et al., 2011) and induces market inefficiencies (Strand, 2005; Gokalp et al., 2017; Balafoutas et al., 2015), surprisingly little is known about the phenomenon. A few studies model the interaction between buyers and sellers theoretically (Yaniv, 1993; Fedeli and Forte, 1999; Boadway et al. 2002; Chang and Lai, 2004, Kleven et al., 2011; Abraham et al., 2017), but to our knowledge, there is no empirical evidence on how collaborative tax evasion is negotiated.

We advance the literature in a new direction by examining collaborative tax evasion in naturally occurring markets. Field experiments have been established as an especially promising approach to study tax evasion (e.g., Slemrod and Weber, 2012; Hallsworth, 2014). We run a large-scale natural field experiment in which we take the role of consumers and vary if we request an invoice for the delivery of a service $!^{1}$

The aim of our paper is twofold. First, we quantify the fraction of businesses that approach consumers with the intention to evade. Theory predicts that the willingness to evade taxes decreases with the number of agents that are aware of the transaction (Kleven et al., 2016; Naritomi, 2016) and increases when the other party credibly commits to collaboration (Boadway et al., 2002; Chang and Lai, 2004). We study how the fraction of evaders varies with different market regulations and signals send by consumers.

Second, we quantify how much consumers can save if they agree to evade, i.e., their evasion rent. Theory predicts and survey evidence shows that the financial benefit is an important parameter in sellers' and buyers' decisions to evade taxes (European Commission, 2014). While several countries have introduced tax subsidies to incentivize reporting to tax authorities (e.g., $61 \%$ of European countries, Williams and Nadin, 2014), little is known about how reporting incentives relate to the expected savings in case of evasion.

The experiment relies on job advertisements posted in 42 German cities (similar designs have been used by, e.g., Leibbrandt and List, 2014; Flory et al., 2015; Mas and Pallais, 2017). We searched for painting and flooring contractors to conduct renovation services of varying intensity. The home repair and remodeling sector is a prominent example of a sector in which the prevalence of tax evasion is estimated to be high (e.g., European Commission, 2014). The advertisements were posted to online markets, which

1 In a natural field experiment the subjects are naturally undertaking the tasks without knowing that they are part of an experiment; see the taxonomy of experiments proposed by Harrison and List (2004). 
are increasingly used to sell and order services of all kinds (Initiative D21, 2015, 2016) ${ }^{2}$ We considered two markets which differ in their degree of regulation.

Almost 2,900 businesses applied for the jobs and sent us the consumer - a price proposal. They randomly received one of seven treatments that specify the contract conditions. The main outcome of interest is whether the contractors who were initially interested still want to execute the job once they have learned about our conditions.

We use two treatments to quantify the fraction of businesses that intend to evade. In the baseline treatment, we do not mention whether we need an invoice or not. Consequently, businesses should accept the treatment independent of their declaration intention. In the invoice treatment, we stress that an invoice is needed to deduct the service costs from the tax bill $]^{3}$ In Germany, a tax subsidy allows consumers to recover $20 \%$ of labor costs of repairs when they prove the transaction through an invoice. Since businesses have to expect that public authorities will learn about the transaction, this treatment should only be accepted by those who intend to declare the transaction. The difference between the acceptance rates of the two treatments informs us about the fraction of businesses that approach us with the intention to collaboratively evade taxes.

We find a large and statistically significant decrease of the acceptance rate for the job when we request an invoice. Overall, $56 \%$ of businesses approach us with the intention to evade. However, we find stark differences by market. In the regulated market, the fraction of evaders is close to zero. In contrast, in the unregulated market almost three out of four contractors intend to evade. The market difference seems to be largely driven by a selection effect as $43 \%$ of the businesses operating in the unregulated market seem to be informal. While the regulated market restricts access to formal businesses and keeps track of businesses' credentials, no such regulations are in place in the unregulated market.

We implement five treatments to study if the fraction of evaders increases when consumers signal their willingness to collaborate. Since collaborative tax evasion is related to price discounts, asking for them may signal consumers willingness to participate in collaborative tax evasion. However, price pressure has only a weak effect on businesses' intention to declare. The fraction of evaders increases to $64 \%$ when we ask for a $20 \%$ discount of the initial price offer. In contrast, the fraction of evaders increases to $80 \%$ when we signal our willingness to collude more directly by asking for a "cash" price.

Using the variation of price proposals between businesses, we estimate that consumers can save on average $25 \%$ if they choose a business that has the intention to evade. Hence, consumers can save at least as much by evasion as by using the tax subsidy of $20 \%$. Holding

2 Survey evidence suggests that one in four Americans use the gig economy for side hustling without declaring the income on taxes (https://www.finder.com/side-hustle).

3 Our approach is related to Kerschbamer et al. (2016) who investigate fraudulent seller behavior by manipulating whether the consumer mentions that repair costs are covered by an insurance. 
businesses constant (within variation), we find that contractors who approached us with the intention to declare would give a discount that matches the German value added tax (VAT) of $19 \%$ if we ask for a cash price. In contrast, contractors who approached us with the intention to evade propose a cash price that is $35 \%$ lower than the invoice price that they announce when we ask for it, presumably to deter us from requesting an invoice.

Our research relates to several fields in literature. First, we contribute to the growing literature that stresses the importance of third party information for tax compliance (e.g., Kleven et al., 2011; Pomeranz, 2015; Naritomi, 2016). We show that in business to consumer sales, the majority of contractors propose prices with the intention to evade taxes. The fraction of evaders is particularly high when the likelihood that an informed third party (the consumer or the marketplace) will report the transaction is lower. Second, we add to the mostly theoretical literature on collaborative tax evasion by showing that contractors indeed reward with an evasion rent consumers who are willing to collaborate. Third, we contribute to the literature that aims to estimate the prevalence of tax evasion. Existing studies quantify the amount of income not reported to tax authorities (e.g., Kleven et al. 2011) or the fraction of individuals who admit that they demanded or supplied undeclared services in the past (e.g., Feld and Larsen, 2012, European Commission, 2014) 4 We are the first to quantify the potential for tax evasion on the supply side.

The remainder of the paper is structured as follows. Section 2 contains theoretical considerations. The experimental design and summary statistics are described in Section 3. While businesses' initial intention to evade is studied in Section 4, Section 5 describes their reaction to consumers' collaboration signals. Section 6 contains the results on the evasion rent. A discussion follows in Section 7, Section 8 concludes.

\section{Theoretical considerations}

We present a simple model of businesses' behavior in order to provide a framework for our experimental design and to highlight the factors that determine the decision to evade (following, e.g., Becker, 1968; Allingham and Sandmo, 1972). Businesses can either be formal $F$ or informal $I$. While informal businesses can only propose a price that involves evasion $p^{E}$, formal businesses can choose between an evasion price $p^{E}$ and a declaration price $p^{D}$. The decision to act as informal business can be explained by two reasons. First, individuals may decide against a business registration when they earn little self-reported income (Kleven et al., 2011). Registration is costly and implies the hassle of dealing with

4 A variety of indirect approaches exist to quantify non-compliance using traces of income, noncompliance or macro-based inference. For an overview see, e.g., Slemrod and Weber (2012). 
bureaucracy $5^{5}$ Second, some individuals can not register their business, e.g., because of a lack of permission to work in Germany or of permission from the main employer to do a second job. Since we advertise small-scale jobs, we assume that the decision to formally register the business is independent of the interaction with us.

The ability to propose $p^{D}$ determines the type of market on which businesses operate $m \in\{0,1\}$. Informal businesses can only participate in the unregulated market $m=0$. Formal businesses can choose to operate in the regulated or in the unregulated market. Apart from the access restriction, the two markets differ in the possibility to keep track of businesses' identities. This is only possible in the regulated market $m=1$.

While informal businesses will always evade, formal businesses evaluate the benefits and costs of collaborative tax evasion in order to decide whether to evade the sale of one additional unit. Therefore, we assume that the universe of businesses consists of three groups - informal businesses $\gamma_{I}$, formal businesses that evade $\gamma_{F}$ and formal businesses that declare $\omega$. We aim to quantify the fraction of evaders $\gamma=\gamma_{I}+\gamma_{F}$ in our experiment and analyze how this fraction varies with market regulation and signals sent by consumers.

Since only formal businesses can react to the incentives created by market regulation and the signals sent by consumers, in the following, we outline the determinants that influence their declaration decision before we formulate our hypotheses. We consider formal businesses to be risk-neutral when selling one unit of their service for the net market price $q$ on market $m$. In case of declaration, the transaction will be taxed (e.g., VAT, income tax) by $\tau \in[0,1]$. For simplicity, we assume that businesses can shift the burden of taxation to consumers and propose a gross price $p^{D}$ (see first row of Table 1). Assuming that businesses face constant costs of providing the service $c$ which have to be subtracted from the market price, businesses' profits amount to $y^{D}$ if they declare.

In case of evasion, businesses share a fraction $\beta \in[0,1]$ of the evasion amount $(q \tau)$ with consumers. In their choice of $\beta$, businesses have to consider that consumers who demand declared work are rewarded with a tax subsidy $k \in[0,1]$ on the gross price $p^{D}$. If $\beta>0$, consumers profit from a lower price $p_{E}$ which amounts to the net market price plus the fraction of the evasion amount that the business keeps $(1-\beta)$. We denote the relative difference between $p^{D}$ and $p^{E}$ as consumers' evasion rent $\epsilon=\frac{p^{D}-p^{E}}{p^{D}}$. Businesses' profits amount to $y_{E}$ which implies $y_{E}>y_{D}$ as long as $\beta<1$.

If businesses decide to evade taxes they face a probability of detection $\pi \in[0,1]$. We

5 In Germany, the Trade and Crafts Code regulates who is allowed to practice as a craftsman. We chose jobs which can be registered without a specific qualification. However, tradesmen have to become a member of the Chamber of Commerce and enter the register of qualified craftsmen. Registration in the Chamber of Commerce is costly; for example, in Freiburg it amounts to administrative fees of 175 Euros plus annual fees which start from 141 Euros and increase with profits. In addition, tradesmen are required to register their business for tax purposes. The registration costs vary across cities within a range from 10 to 50 Euros. Once registered, regular tax declarations are mandatory. 
Table 1: Consumer prices and business profits under declaration and evasion

\begin{tabular}{lll}
\hline & Consumer price & Business profit \\
\hline Declaration & $p^{D}=q(1+\tau)$ & $y^{D}=q-c$ \\
Evasion & $p^{E}=q(1+\tau(1-\beta))$ & $y^{E}=q(1+\tau(1-\beta))-c$ \\
\hline
\end{tabular}

follow Naritomi (2016) and Kleven (2014) and model the detection probability as the product of the exogeneously determined audit rate $a \in[0,1]$ and the governments' ability to detect evasion during an audit $d \in[0,1], \pi \equiv a d$. In our experiment, $a$ is given while the ability to detect evasion $d$ is influenced by market regulation and consumers' signals.

First, following the idea that the number of internal or external parties to which an evader exposes himself is a key determinant of collusion (Kleven et al., 2016, Naritomi, 2016), we assume that $d$ decreases by $\lambda$ if formal businesses operate in the unregulated market $m=0$, as it is impossible to track identities. Second, in line with the idea that the probability of detection decreases when consumers credibly commit to collaborate (Boadway et al., 2002; Chang and Lai, 2004), we assume that $d$ decreases with the strength of consumers' signal that they are willing to collaborate $\eta \in[0,1]$. The ability to detect evasion is thus $d=1-\lambda(1-m)-\eta$. This leads to the probability of detection $\pi \equiv$ $a(1-\lambda(1-m)-\eta)$. If detected, businesses have to pay a sanction $s$ and return their share of evaded taxes; they receive $y^{D}-s$. If not detected they receive $y^{E}$.

Businesses are assumed to be heterogeneous in their moral costs of evasion $\alpha_{i}$ which are private information. They vary with businesses' commitment to tax laws or personal sensitivity to norms (e.g., Chang and Lai, 2004). An increasing number of studies (e.g., Abeler et al., 2014; Fischbacher and Föllmi-Heusi, 2013) provide experimental evidence for the heterogeneity of moral costs across individuals. Moral costs are assumed to follow a continuous uniform distribution on the unit interval, i.e., $F(\alpha)=\alpha$. In other words, $\alpha$ percent of businesses have moral costs of less than or equal to $\alpha$ (Le Maux et al., 2018). Businesses will decide to declare when the expected revenues from declaration are larger than the expected revenues of evasion weighted with the moral costs, see equation 1

$$
y^{D} \geq\left(1-\alpha_{i}\right)\left[\pi\left(y^{D}-s\right)+(1-\pi) y^{E}\right] .
$$

Since formal businesses are only heterogeneous in their moral costs, $\alpha$ will separate the evaders from the declarers. Equation (1) can be rewritten as

$$
\alpha_{i} \geq 1-\frac{y^{D}}{\pi\left(y^{D}-s\right)+(1-\pi) y^{E}} .
$$

Formal businesses with moral costs lower than or equal to $\alpha$ will evade. Since busi- 
nesses are distributed on the unit interval, the fraction of formal businesses evading is given by equation (3).

$$
\gamma_{F} \equiv \alpha=1-\frac{y^{D}}{\pi\left(y^{D}-s\right)+(1-\pi) y^{E}}
$$

Taking into account informal businesses, we obtain the total fraction of evaders

$$
\gamma=\gamma_{F}+\gamma_{I} \cdot(1-m)
$$

Based on this model we formulate the following testable hypotheses:

Hypothesis 1 The fraction of evaders is higher in the unregulated market $\gamma_{m=0}>\gamma_{m=1}$.

Hypothesis 1 is a consequence of two effects. First, there might be a selection effect. Whereas formal businesses can operate in regulated $m=1$ and unregulated $m=0$ markets, informal businesses can only operate in the unregulated market $m=0$. Thus, the fraction of evaders should be higher in the unregulated market as informal businesses are included $\left(\gamma=\gamma_{F}+\gamma_{I}\right.$ if $m=0$ vs. $\gamma=\gamma_{F}$ if $\left.m=1\right)$. Second, there might an incentive effect. The fraction of evaders should be higher in the unregulated market as formal businesses face a lower probability of detection $(\pi \equiv a(1-\lambda-\eta)$ if $m=0$ vs. $\pi \equiv a(1-\eta)$ if $m=1)$.

Hypothesis 2 The fraction of evaders increases with the strength of the consumers' signal about their willingness to collude.

In the experiment, we send signals of different strength that we are willing to collaborate. A stronger signal implies that the parameter $\eta$ increases which in turn decreases government's ability to detect evasion $d$. In line with previous theoretical studies, we expect that the related decrease in the expected probability of detection increases the fraction of formal businesses that evade $\left(\frac{\partial \gamma_{F}}{\partial \pi} \frac{\partial \pi}{\partial d} \frac{\partial d}{\partial \eta}>0\right)$.

Hypothesis 3 The evasion rent is positive $\epsilon>0$ and at least matches the tax subsidy $\epsilon \geq k$.

Businesses that aim to convince consumers to collaboratively evade taxes need to propose a price $p^{E}<p^{D}$ to offset possible costs of evasion that the consumer has to expect. Modeling the decision of consumers is outside the scope of our paper. However, similar to businesses, they face a probability of detection and sanctions in case of detection. Since consumers benefit from a tax subsidy when honestly demanding services, following Naritomi (2016), we hypothesize that businesses propose an evasion rent that is positive and at least matches the tax subsidy. 


\section{Experimental design}

\subsection{Experimental setup}

We conduct a natural field experiment in online markets to investigate businesses' behavior. Online markets are increasingly used to sell and order services of all kinds. The number of internet users who order services online increased from $25 \%$ in 2015 to $36 \%$ in 2016 (Initiative D21, 2015, 2016). Craftsmen services increasingly realize that online markets offer an opportunity for their business (stated by $70 \%$ in 2014, Zentralverband des Deutschen Handwerks, 2014). In 2016, $46 \%$ of craftsmen reported that they had already taken action, $38 \%$ reported that they would take action to participate in digital markets (Zentralverband des Deutschen Handwerks, 2016).

The experiment consisted of a two-step procedure illustrated in Figure 1. In the first step, we advertised one-time painting and floor installation jobs. The advertisements did not specify the contract conditions (in particular, whether or not an invoice is requested). Interested contractors applied by sending a price proposal via email. In this way, we obtained information on the number of businesses initially interested in the job and their proposed prices. In the second step, every contractor who sent a price proposal was informed about the contract conditions. Our main variable of interest is whether the contractors were still willing to do the job after they had learned the contract conditions.

Figure 1: The experimental set-up

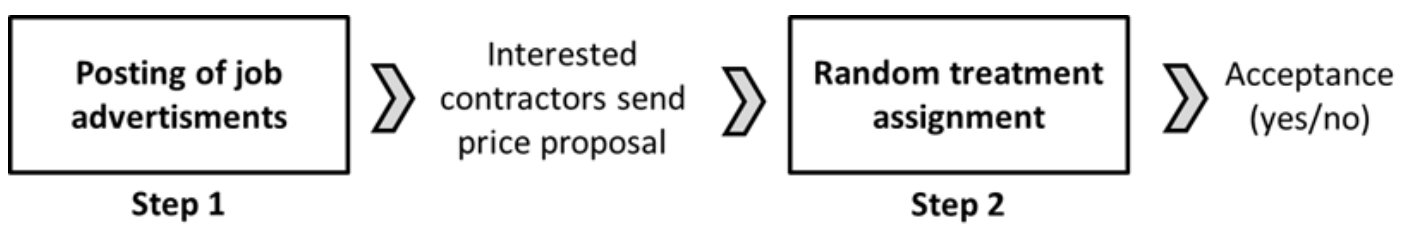

The experiment was implemented in a $2 \times 7$ design in which we varied the job advertisement and contract conditions. In the first advertisement, we searched for contractors to paint two rooms (40sqm). In the second advertisement, we searched for contractors to install parquet in two rooms (40sqm). In the following, we refer to this setup as our main experiment. To understand if our main results apply to other volumes of the service, we posted two additional advertisements in which we varied the number of rooms (see Appendix A.2 for details). In the following, we refer to this setup as our extension.

We focus on painting and floor installation for two reasons. First, tax evasion is estimated to be rife in the home repair and remodeling sector. Among the Europeans who admit to not having declared services, the domain most often mentioned is undertaking 
repairs or renovations (admitted by 19\%, European Commission, 2014). Second, painting and floor installation are very convenient for a large-scale natural field experiment. Many jobs require a visit to the site to estimate the price. Our jobs are less complex such that a comprehensive description allows contractors to propose a price without a viewing.

The advertisements mirror those for similar jobs in online markets (wording is shown in Appendix A.3. We used pretests to make sure that the ads include all details that are important for contractors to propose a price (e.g., the size and shape of the room/wall/floor). Contractors were asked to send a price proposal without material, which would be provided by us ${ }^{6}$ We focus on the labor costs for two reasons. First, price proposals should be independent of the quality of the material. Second, the tax subsidy only applies to labor costs 7 Hence, comparing the consumers' profit from evasion to the tax subsidy (hypothesis 3) is only possible when the cost of materials is excluded. The advertisements emphasized that it is not possible to visit the site beforehand. Requesting a price proposal prior to personal interaction is common in online markets 8

The advertisements were posted to two online platforms in Germany. The platforms differ in their degree of regulation. In market $\mathrm{R}$ (for regulated), contractors are only allowed to participate if they have a registered business. They have to provide their credentials, which are verified by the platform. Customers can access the information and rate businesses that have provided a service. The market access is further regulated by a small monthly entry fee for businesses. In contrast, market $U$ (for unregulated) is a platform with few restrictions. People can use a pseudonym and identities are not verified. There is no possibility to rate transaction partners and registration is free.

We posted the advertisements for painting two rooms in 42 German cities between August 2016 and May 2017 (see map in Appendix A.4). All state capitals and at least one further city per state (except for in the city states) were included. The cities were chosen with respect to population size and distance from each other. Since contractors may operate in broader regions, large distances help to minimize the number of offers per contractor. The advertisements for floor installation in two rooms were posted in 22 of these cities between November 2016 and May 2017.

Each advertisement was posted on Monday at 10 am and remained online until Friday at $5 \mathrm{pm}$. After at most 24 hours, we sent a negative reply to contractors who accepted our conditions. In the course of the experiment, we hired one contractor per treatment 9

6 Since contractors prefer to bring their own tools, e.g., brushes, we did not provide these items.

7 Households can deduct $20 \%$ of the labor costs from their income tax liability (up to 1,200 Euros (about 1,400 US Dollars), 35a Abs. 3 EStG).

8 We checked if excluding the possibility to view the rooms beforehand influences the number of observations and average prices proposed. We posted to the regulated market on the same day for the same city our advertisement as well as a slight modification which does not include the sentence that a visit is impossible. We find no significant differences in the number of applications and prices.

9 We hired randomly drawn contractors who accepted the treatment conditions to complete renovation 


\subsection{Treatments}

The experiment is implemented as a between-subject design in which we randomly assign seven contract conditions (treatments) across interested contractors on the city and advertisement level. Table 2 provides an overview of the conditions. The wording is shown in Appendix A.3.

Table 2: Treatments

\begin{tabular}{ll|ccc}
\hline \hline & Demand discount & No & $10 \%$ & $20 \%$ \\
Demand invoice & & & \\
\hline No (TB Baseline) & $\mathrm{TB}_{0}$ & $\mathrm{~TB}_{10}$ & $\mathrm{~TB}_{20}$ \\
Yes (TI Invoice) & $\mathrm{TI}_{0}$ & $\mathrm{TI}_{10}$ & $\mathrm{TI}_{20}$ \\
\hline Qualitative & \multicolumn{3}{|c}{$\mathrm{TQ}$} \\
\hline
\end{tabular}

We implement two treatments $\left(\mathrm{TB}_{0}, \mathrm{TI}_{0}\right)$ to quantify the fraction of businesses that approach consumers with the intention to evade taxes (fraction of evaders $\gamma$ ). We assume that contractors propose prices with the intention to evade or to declare. In the baseline treatment $\mathrm{TB}_{0}$, we confirm the proposed price and specify the time frame in which the job should be executed. Contractors are informed that we received several offers and will make a decision in the next few days. They are asked to send us an email (and propose a possible day) if they agree with our conditions. We do not specify whether we need an invoice. Since the email contains the same information as the advertisement, all initially interested contractors should accept the conditions. Reasons why some may not reply are, e.g., that they got other jobs in the meantime or forget to answer.

In the invoice treatment $\mathrm{TI}_{0}$, we add the sentence "I need an invoice, I would like to deduct the costs from taxes.". The tax subsidy for households demanding home repair, maintenance, or remodeling services has been introduced in 2006 as part of an initiative against tax evasion. Its existence allows us to signal that public authorities will learn about the transaction if the contractor accepts. As pointed out in Section 2, there are two types of contractors that will not accept the invoice treatment. First, informal businesses that are not able to issue an invoice will decline. Second, formal businesses that are able to issue an invoice but have proposed a price with the intention to evade will reject.

The two treatments allow us to identify the fraction of evaders $\gamma$ based on two assumptions. First, we assume that all businesses who accept the invoice treatment would actually declare the transaction. It would be highly irrational to issue an invoice and evade since contractors face a high likelihood of detection due to our use of the invoice for tax deductions and possible cross checking by public authorities. Second, we assume that

services in a refugee camp. In all treatments, we insisted on receiving an invoice. 
contractors who agree to issue an invoice if we explicitly ask for it would also issue an invoice if we did not ask for it. Since contractors operate in highly competitive environments, it is unlikely that they propose prices without having a clear declaration intention. This implies that there is an equal proportion of declarers in the baseline and the invoice treatment. If one of these assumptions is violated, the results represent a lower-bound estimate of the fraction of those who intend to evade (see Appendix A.5 for further details and a discussion of the identification strategy.)

To study if businesses are more willing to evade when consumers signal their willingness to collude, we run five treatments. Four contract conditions are implemented to study businesses' behavior when consumers ask for a price discount. Asking for a price discount may signal consumers' willingness to collude. In the baseline treatments $\mathrm{TB}_{10}$ and $\mathrm{TB}_{20}$, we modify the text from $\mathrm{TB}_{0}$ by asking for a $10 \%$ or $20 \%$ discount. We expect that a fraction of the businesses who proposed a price with the intention to declare switch to evasion when they receive a baseline discount treatment. No such reaction is possible among the contractors that receive the modified invoice treatment $\left(\mathrm{TI}_{10}, \mathrm{TI}_{20}\right)$. We expect to observe a lower decline of acceptance rates in the baseline discount treatments than in the invoice discount treatments. This should result in a higher fraction of evaders.

In treatment TQ, we assess contractors' willingness to deviate from their initial declaration intention when consumers send a stronger collusion signal. The treatment text consists of two questions. We ask if the price includes an invoice and how much the price would be if we would pay cash. The word "cash" is commonly used as a collusion signal since cash payment ensures that a transaction cannot be tracked (e.g., Fooken et al., 2015) 10 In contrast to the baseline and invoice treatments, we infer the willingness to issue an invoice or refrain from doing so from the willingness to quote an invoice and a cash price. The two prices allow us to provide additional evidence on the evasion rent.

\subsection{Variables of interest}

In all treatments, we are interested in the proposed price(s) and the reaction to our treatment. German price regulations require contractors to quote gross prices when trading with consumers ( $\S 1$ Abs. 1 PAngV) ${ }^{11}$ However, in our sample only $7 \%$ comply with the law by sending a gross price. The large majority of contractors (90\%) do not specify whether the price is gross or net. A small fraction of contractors (3\%) explicitly write that the proposed price is net, a third of which mention that taxes have to be added.

\footnotetext{
10 Immordino and Russo (2017) find a positive link between VAT evasion and cash withdrawals at Automated Teller Machines (ATMs). Acknowledging the link between cash payment and tax evasion, the German legislator has decided to exclude any transaction that has been paid cash from tax deductions.

${ }^{11}$ In online transactions, contractors have to quote gross prices and explicitly inform consumers that the price includes sales taxes ( $\$ 1$ Abs. 2 Nr. 1 PAngV).
} 
Contractors may mistakenly assume that they are negotiating with a business. In business to business transactions the negotiation of net prices is the rule. However, offering net prices can also be a strategy for proposing tax evasion. ${ }^{12}$ We use contractors' original price offers to calculate the discount requested in treatments $T_{10}$ and $T_{20}$, to check that offers are balanced across treatments, and to calculate the evasion rent.

The main variable of interest in the baseline and invoice treatments is whether interested contractors are still willing to do the job after they have learned the contract conditions. We classify contractors as having rejected if they do not respond or modify or reject the conditions. The remaining contractors are classified as having accepted. The coding of responses was verified by three raters. In treatments TB and TI, $0.4 \%$ of answers could not be interpreted unambiguously. They are discarded in the analysis.

With regard to treatment TQ, we are interested in the initial declaration intention and the fraction of those that are willing to deviate from that intention. If the contractor responds that the initial price includes an invoice, he is classified as having approached us with the intention to declare. If we are informed that the price is "cash", the contractor is coded as having approached us with the intention to evade. If the contractor proposes a second price for the option that he did not initially propose, he is coded as being willing to deviate from the initial intention. In addition, we record the "cash price" and the "invoice price" to obtain additional evidence on the evasion rent 13 We consider all subjects in the analysis who provided unambiguous answers, i.e., they communicated either both prices or the response allowed us to conclude that they are not willing or able to quote the missing price. Since treatment TQ is less standardized than treatments TB and TI, we repeated some clarifying questions in case of ambiguity. In $5 \%$ of the cases, the answer could still not be unambiguously coded. Those cases are discarded in the analysis.

\subsection{Summary statistics}

In total, 3,226 contractors applied to our advertisements. A fraction of $9 \%$ did not comply with the requirements posted in the advertisement, e.g., the contractors asked for a call or did not send a (total) price $1^{14}$ Since it was impossible to treat those subjects in

\footnotetext{
12 If contractors proposed gross or unspecified prices, we use these values in the treatments and analysis. For the $3 \%$ who proposed net prices, we randomly used either calculated gross prices or the given net price. Both approaches may lead to biases. Using the net price can imply that in the invoice treatment contractors the treatment and inform us that taxes have to be added. Using calculated gross prices, we signal the intention to declare in the baseline treatment due to the price increase as a result of the VAT. While both approaches are not ideal, the difference in the acceptance rate between the invoice and baseline treatments as well as evasion rent are the same if either group is discarded in the analysis.

${ }^{13} \mathrm{It}$ is possible that a contractor reports a cash price but stresses that it includes an invoice. In these cases, the cash price deviates from the invoice price because contractors reward immediate payment without deviating from the intention to declare. Such prices are not classified as "cash" price.

14 The reasons for non-compliance with our advertisement are as follows: $3.5 \%$ asked for a call or visit prior to sending a proposal; $2.6 \%$ did not send a (total) price but asked us for a price proposal or
} 
a standardized way or to compare their behavior to that of those complying with our conditions, we exclude them from the sample. Additionally, we discard subjects that provided an ambiguous answer, see Section 3.3. The final sample thus consists of 2,900 observations, 2,530 of which participated in the main experiment, 370 in the extension.

Table 3: Number and average prices of offers by market and job

\begin{tabular}{lcccccc}
\hline \hline & \multicolumn{2}{c}{ Total } & \multicolumn{2}{c}{ Market R } & \multicolumn{2}{c}{ Market U } \\
\cline { 2 - 7 } & $\mathrm{N}$ & Mean price & $\mathrm{N}$ & Mean price & $\mathrm{N}$ & Mean price \\
\hline Total & 2,530 & 332.0 & 613 & 463.4 & 1,917 & 290.0 \\
Painting & 1,800 & 253.4 & 383 & 343.2 & 1,417 & 229.1 \\
Flooring & 730 & 525.7 & 230 & 663.5 & 500 & 462.4 \\
\hline
\end{tabular}

Table 3 gives an overview of the overall number of individuals treated in the main experiment, as well as by job and market ${ }^{15}$ We received more applications for the painting job than for the floor installation job. The number of observations is higher for two reasons. First, we posted the advertisement for the painting job in twice as many cities as the flooring job. Second, the average number of offers per city is higher for the painting job, which may be explained by the lower complexity of this service. ${ }^{16}$ We received 1,917 offers in the unregulated market and 613 in the regulated market. This can be explained by differences in access restrictions, described in Section 3 . Table 3 shows that differences across jobs and markets are also observed with regard to average proposed prices. The average proposed price is about $50 \%$ higher in the regulated market. Installing parquet floor in two rooms costs on average more than twice as much as painting two rooms.

In Table 4, we investigate whether the proposed prices and shares of applications by market and job advertisement are balanced across treatments. The average proposed price is similar across treatments (column 1), the mean differences are not statistically significant (column 3). The table shows that we observe a large range of proposed prices in all treatments (columns 4 and 5) ${ }^{17}$ Kolmogorov-Smirnov tests indicate that the price

communicated a price per hour/square meter; $1 \%$ sent offers including the material; $1 \%$ requested very detailed information which would have implied differences in information across contractors; $1 \%$ sent unspecific offers. While it is more likely that those that ask for a call are businesses that intend to declare, it is more likely those that ask us for price proposals or send unspecific offers are businesses that intend to evade. We conclude that neglecting those that did not comply with our requirement does not cause a selection issue.

15 Summary statistics of the extension are reported in Appendix A.2.

16 On average we received 46 offers per city for the painting job and 31 offers for the flooring job.

17 The prices may vary due to differences in the expected work effort, regional characteristics, or market competition. As will be shown in Section 6. the price also includes information about the intention to declare. An example of offers from the lower end of the price distribution is a student who wants to earn money without having a registered business and the appropriate qualification. An example of offers from the upper end of the distribution is a business which has full order books but would do 
Table 4: Balancing of pre-treatment characteristics

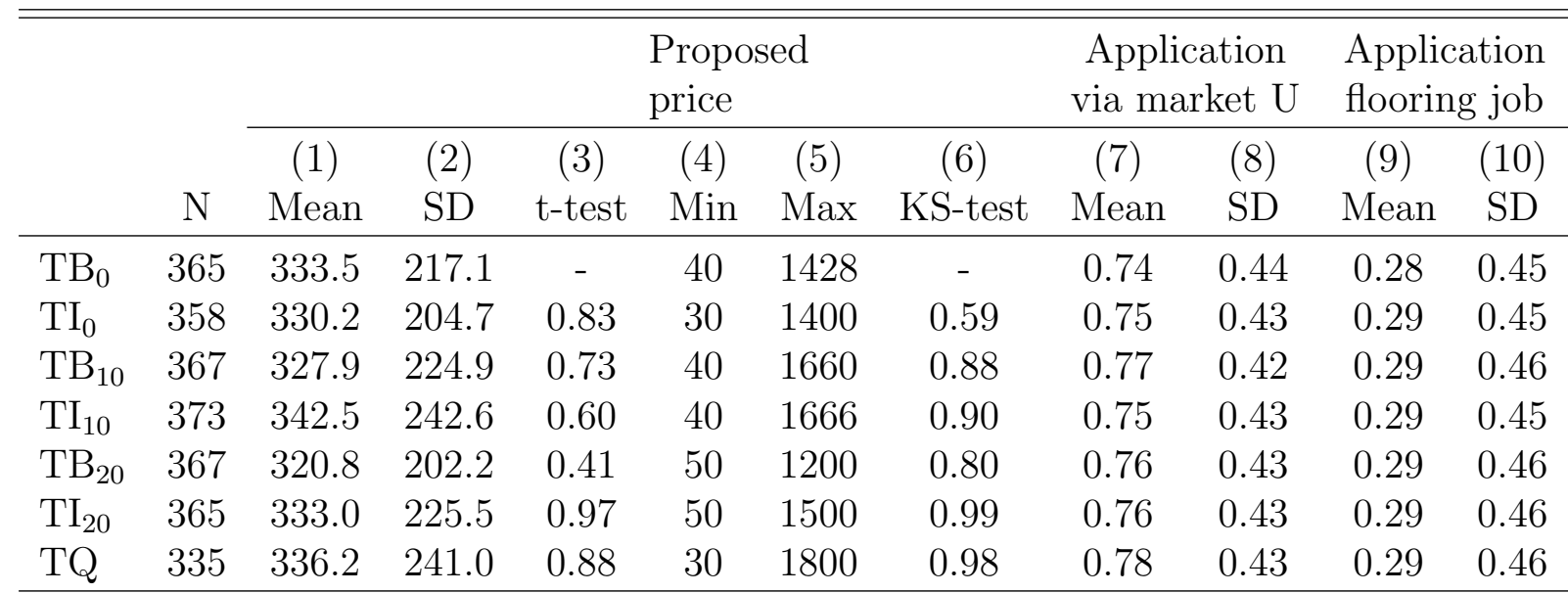

Note: Columns (1), (4), and (5) report prices in Euro. SD is the standard deviation. Column (3) reports p-values from t-tests of differences between mean prices relative to the mean price in the baseline treatment. The lowest and highest price proposal of each treatment are presented in columns (4) and (5). Column (6) reports p-values from Kolmogorov-Smirnov tests (KS-test) of equality of distributions of prices relative to the price distribution in the baseline treatment. In columns (7) and (9), we show the shares of applications in market $U$ and for the flooring job.

distribution is not statistically different across treatments (column 6). We do not find any significant differences in the shares of the two markets or the shares of the two advertised jobs across treatments. The results indicate that the randomization was successful.

\section{Businesses' initial intention to collaboratively evade taxes}

\subsection{The effect of asking for an invoice}

The baseline and invoice treatments $\left(\mathrm{TB}_{0}, \mathrm{TI}_{0}\right)$ allow us to quantify the fraction of evaders $\gamma$. Figure 2 shows the contractors' willingness to accept the contract conditions. The baseline treatment is accepted by $94 \%$ of interested contractors. Although we do not make any amendments to the contractors' offer, $6 \%$ do not reply, e.g., because they got other jobs in the meantime. Only $41 \%$ accept the conditions of the invoice treatment.

The difference between acceptance rates in the baseline and invoice treatment identifies the causal effect of requesting an invoice on businesses' willingness to do the job at the proposed price. Requesting an invoice leads to an impressive and statistically highly significant decline of available offers by 53 percentage points (ppts) (t-test: $p=0.000$; $\mathrm{n}=723){ }^{18}$ We divide the absolute difference by the acceptance rate in the baseline treatment to obtain the fraction of evaders. The overall fraction of those who intend to evade amounts to $56 \%$. To assess if the fraction is significantly different from zero, we

the job for an excessively high price (deterrence pricing). While it is possible that prices are related to quality, we cannot assess to what extent this is the case.

18 We obtain the same result if we use a non-parametric test like Fisher's exact test. 
Figure 2: Acceptance rates in the baseline and invoice treatment

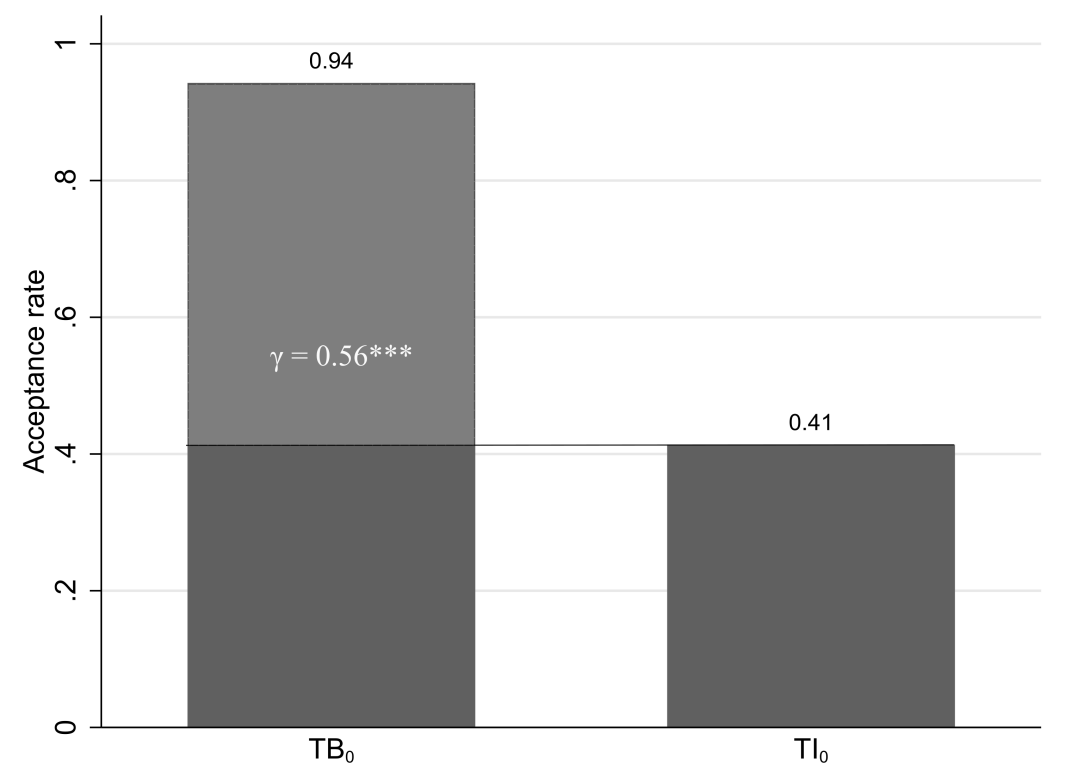

Note: The bars show the proportion of applicants accepting our conditions in the baseline $\mathrm{TB}_{0}(\mathrm{n}=365)$ and the invoice treatment $\mathrm{TI}_{0}(\mathrm{n}=358)$. The fraction of evaders $\gamma$ is calculated as the difference between the acceptance rates divided by the acceptance rate of the baseline treatment. Standard errors are obtained by bootstrapping with 499 replications. $\mathrm{p}$-values are marked as $* \mathrm{p}<0.1, * * \mathrm{p}<0.05, * * * \mathrm{p}<0.01$.

obtain its empirical bootstrap distribution (499 replications, sampling with replacement), which indicates high statistical significance ( $\mathrm{t}$-test: $\mathrm{p}=0.000 ; \mathrm{n}=723$ ).

To assess the robustness of this result with respect to city- and quarter-specific effects, we consider a linear regression model. We pool the observations from $\mathrm{TB}_{0}$ and $\mathrm{TI}_{0}$ and regress contractors' acceptance on the invoice treatment dummy and city and quarter dummies (column 1, Table 5). Coefficients are reported in Panel A; the fraction of evaders obtained from predicted values is presented in Panel B. Compared to the descriptive result in Figure 2, the treatment effect and the fraction of evaders are unchanged if we control for differences in the average acceptance rates by city and quarter.19

According to hypothesis 1 , we expect that the fraction of evaders varies with the degree of market regulation because of a selection effect and a higher detection probability in the regulated market. In Figure 3, we plot the acceptance rates and the fraction of evaders by marketplace. Contractors' acceptance of the baseline treatment $\mathrm{TB}_{0}$ is similar. In contrast, the acceptance of the invoice treatment $\mathrm{TI}_{0}$ differs substantially. If consumers ask for an invoice in the regulated market, the number of available offers decreases by 2 ppts compared to the baseline treatment. The effect is not significantly different from zero (t-test: $\mathrm{p}=0.716 ; \mathrm{n}=185$ ). In contrast, the acceptance rate decreases by $70 \mathrm{ppts}$

\footnotetext{
${ }_{19}$ We obtain the same result if we run probit estimation (results available upon request). We opt for linear regression, which allows us to interpret interaction terms in a straightforward way.
} 
Table 5: Regression results and fractions of evaders

\begin{tabular}{|c|c|c|c|c|}
\hline & $(1)$ & $(2)$ & $(3)$ & $(4)$ \\
\hline \multicolumn{5}{|c|}{ Panel A. Coefficients from regression } \\
\hline Invoice treatment $\mathrm{TI}_{0}$ & $\begin{array}{l}-0.532 \\
(0.024)\end{array}$ & $\begin{array}{l}-0.022 \\
(0.033)\end{array}$ & $\begin{array}{l}-0.069 \\
(0.037)\end{array}$ & $\begin{array}{c}-0.069 \\
(0.038)\end{array}$ \\
\hline Market U & & $\begin{array}{c}0.044 \\
(0.035)\end{array}$ & $\begin{array}{c}0.038 \\
(0.036)\end{array}$ & $\begin{array}{c}0.038 \\
(0.036)\end{array}$ \\
\hline Market $\mathrm{U} \times \mathrm{TI}_{0}$ & & $\begin{array}{l}-0.682 \\
(0.047)\end{array}$ & $\begin{array}{l}-0.618 \\
(0.055)\end{array}$ & $\begin{array}{c}-0.617 \\
(0.056)\end{array}$ \\
\hline Proposed price & & & $\begin{array}{l}-0.002 \\
(0.019)\end{array}$ & $\begin{array}{c}0.001 \\
(0.020)\end{array}$ \\
\hline Proposed price $\times \mathrm{TI}_{0}$ & & & $\begin{array}{c}0.094 \\
(0.028)\end{array}$ & $\begin{array}{c}0.095 \\
(0.035)\end{array}$ \\
\hline Floor installing & & & & $\begin{array}{c}-0.034 \\
(0.058)\end{array}$ \\
\hline Floor installing $\times \mathrm{TI}_{0}$ & & & & $\begin{array}{c}-0.001 \\
(0.068)\end{array}$ \\
\hline City fixed effects & yes & yes & yes & yes \\
\hline Quarter fixed effects & yes & yes & yes & yes \\
\hline \multicolumn{5}{|c|}{ Panel B. Fraction of evaders } \\
\hline Overall & $\begin{array}{c}0.564 \\
(0.037)\end{array}$ & $\begin{array}{c}0.560 \\
(0.036)\end{array}$ & $\begin{array}{c}0.560 \\
(0.036)\end{array}$ & $\begin{array}{c}0.560 \\
(0.036)\end{array}$ \\
\hline Market R & & $\begin{array}{c}0.024 \\
(0.051)\end{array}$ & $\begin{array}{c}0.075 \\
(0.053)\end{array}$ & $\begin{array}{c}0.076 \\
(0.054)\end{array}$ \\
\hline Market U & & $\begin{array}{c}0.736 \\
(0.043)\end{array}$ & $\begin{array}{c}0.720 \\
(0.043)\end{array}$ & $\begin{array}{c}0.719 \\
(0.043)\end{array}$ \\
\hline$\Delta$ Markets & & $\begin{array}{c}0.712 \\
(0.068)\end{array}$ & $\begin{array}{l}0.645 \\
(0.07)\end{array}$ & $\begin{array}{c}0.644 \\
(0.071)\end{array}$ \\
\hline $\mathrm{N}$ & 723 & 723 & 723 & 723 \\
\hline
\end{tabular}

Note: Panel A reports results from linear regression of the acceptance rate on the invoice treatment dummy and different sets of control variables. The proposed price is standardized to zero mean and unit variance. Clustered standard errors at the advertisement level reported in parentheses. Panel B reports the fraction of evaders calculated from predicted values of the regression. Standard errors of the fractions of evaders and the difference between markets are obtained from bootstrapping with 499 replications. 
in the unregulated market ( $\mathrm{t}$-test: $\mathrm{p}=0.000 ; \mathrm{n}=538$ ). The fraction of evaders amounts to $2 \%$ in the regulated and $73 \%$ in the unregulated market. The difference between the markets is statistically highly significant (t-test: $\mathrm{p}=0.000 ; \mathrm{n}=723$ ). The regression analysis confirms a large and significant difference of market-specific treatment effects of 68 ppts (column 2, Table 5) when controlling for quarter and city effects.

Figure 3: Fraction of evaders by marketplaces

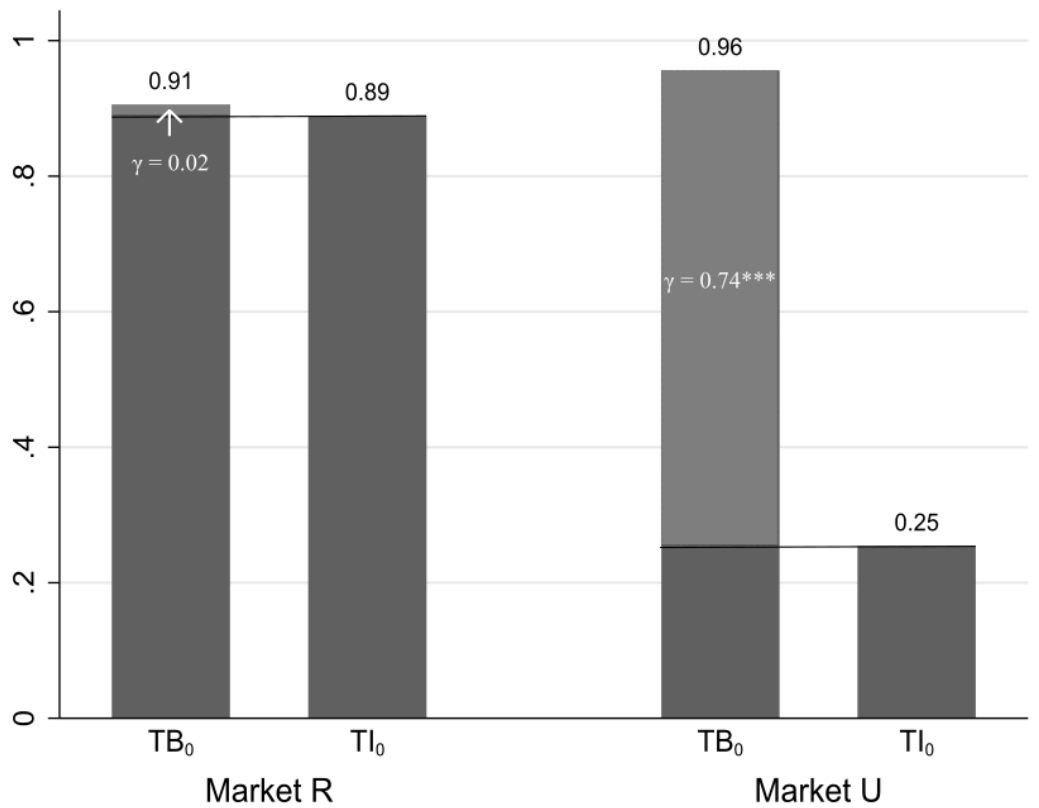

Note: The bars show the proportion of applicants accepting our conditions in the baseline $\mathrm{TB}_{0}(\mathrm{n}=95$ in market $\mathrm{R}, \mathrm{n}=270$ in market $\mathrm{U})$ and the invoice treatment $\mathrm{TI}_{0}(\mathrm{n}=90$ in market $\mathrm{R}, \mathrm{n}=268$ in market $\mathrm{U}$ ). The fraction of evaders $\gamma$ is calculated as the difference between the acceptance rates divided by the acceptance rate of the baseline treatment. Standard errors are obtained by bootstrapping with 499 replications. p-values are marked as * $\mathrm{p}<0.1, * * \mathrm{p}<0.05, * * * \mathrm{p}<0.01$.

Summary statistics in Table 3 show that the businesses operating in the two markets differ in two observable dimensions. Proposed prices and the fraction of applications from flooring contractors are higher in the regulated market. We account for these differences in the regressions. First, we hold the price proposal constant (column 3, Table 5). The table shows that the negative effect of the invoice treatment significantly decreases with the proposed price. However, we find that the large difference across markets is only slightly influenced by proposed prices. The difference between the fraction of evaders by market decreases from 71 to 64 ppts. If we additionally control for advertised job (column 4), the results do not change any further. The fractions of evaders amount to $8 \%$ in the regulated market (insignificant from zero) and $72 \%$ in the unregulated market (significant).

The difference might be explained by the selection and incentive effects related to market regulations (see hypothesis 1 ). We obtain suggestive evidence on the importance 
of these effects by analyzing the responses of contractors who refuse our conditions. In the unregulated market, two thirds of initially interested businesses provide an explanation for their refusal. $65 \%$ of these report that they are informal. One third explain that an invoice would be possible if a higher price would be paid. They seem to be formal businesses that proposed a price with the intention to evade for financial gain. The remaining $2 \%$ demand a call or visit. While it has to be considered that we do not know the reasons of those not replying, the result suggests that the market difference is largely driven by the selection effect, i.e., contractors without a formal business registration being unable to operate on the regulated market. Although the experimental design does not allow us to infer the causal effect of market regulation on contractors' behavior, it suggests that market design is important for the selection of suppliers and their intentions to declare.

\subsection{Robustness to modifications of the sample and job}

We study whether the results reported in column (4) in Table 5 are robust with respect to modifications of the sample. First, we assess if the results remain robust when we drop contractors proposing extremely low or high prices. Summary statistics show that the range of proposed prices is broad (see Section 3.4). Therefore, we exclude the upper and lower $5 \%$ of price proposals for each advertisement sample. Results are presented in column (1) of Table 6. The regression coefficients (panel A) and the fraction of evaders (panel B) are very close to the ones of the full sample reported in Table 5.

Second, we assess whether multiple offers by one contractor affect our results. We identify contractors that applied in more than one city ${ }^{20}$ There are 46 contractors that applied at least twice. We only keep their first offer which implies that we drop 58 observations. The results are robust with respect to this dimension (column 2, Table 6) ${ }^{21}$

Third, we study if the result is the same across jobs in our main experiment. We split the sample by job and report the result for businesses that applied for the painting job and the floor installation job in column (3) and (4), respectively. The overall fraction of evaders is slightly lower in the sample of those who applied to the floor installation job. As before, the market difference is substantial in both types of jobs. It is slightly higher for the painting job than for the floor installation job.

We check if the results also hold for other volumes of the jobs using our extension of

${ }^{20}$ We can unambiguously distinguish contractors that applied through the regulated marketplace. However, in the unregulated market several contractors use pseudonyms like "Privat" (private), "Ich" (I) or their first name. In these cases, it is not possible to conclude that multiple offers were sent by one person. We count the number of offers if contractors used their full name or a distinct business name.

${ }^{21}$ In addition, we check if the reaction to the invoice treatment is different in the first versus subsequent interaction(s). We use all observations on contractors with which we had multiple interactions and regress the response on the invoice treatment dummy, a dummy indicating subsequent observations, and the interaction between them. The interaction is not significant (available upon request). 
Table 6: Summary of results varying the sample and job

\begin{tabular}{|c|c|c|c|c|c|c|}
\hline & $\begin{array}{c}(1) \\
\text { excl. low/ } \\
\text { up } 5 \%\end{array}$ & $\begin{array}{c}(2) \\
\text { excl. } \\
\text { duplicates }\end{array}$ & $\begin{array}{c}(3) \\
2 \text { room } \\
\text { paint }\end{array}$ & $\begin{array}{c}(4) \\
2 \text { room } \\
\text { floor }\end{array}$ & $\begin{array}{c}(5) \\
4 \text { room } \\
\text { paint }\end{array}$ & $\begin{array}{c}(6) \\
1 \text { room } \\
\text { floor }\end{array}$ \\
\hline \multicolumn{7}{|c|}{ Panel A. Coefficients from regression } \\
\hline Invoice treatment $\mathrm{TI}_{0}$ & $\begin{array}{c}-0.042 \\
(0.043)\end{array}$ & $\begin{array}{l}-0.076 \\
(0.043)\end{array}$ & $\begin{array}{c}-0.012 \\
(0.043)\end{array}$ & $\begin{array}{l}-0.087 \\
(0.067)\end{array}$ & $\begin{array}{c}-0.187 \\
(0.053)\end{array}$ & $\begin{array}{c}-0.231 \\
(0.153)\end{array}$ \\
\hline Market U & $\begin{array}{c}0.047 \\
(0.035)\end{array}$ & $\begin{array}{c}0.050 \\
(0.042)\end{array}$ & $\begin{array}{c}0.052 \\
(0.048)\end{array}$ & $\begin{array}{c}0.002 \\
(0.069)\end{array}$ & $\begin{array}{l}-0.035 \\
(0.054)\end{array}$ & $\begin{array}{c}-0.026 \\
(0.060)\end{array}$ \\
\hline Market $\mathrm{U} \times \mathrm{TI}_{0}$ & $\begin{array}{l}-0.611 \\
(0.060)\end{array}$ & $\begin{array}{l}-0.579 \\
(0.063)\end{array}$ & $\begin{array}{l}-0.654 \\
(0.074)\end{array}$ & $\begin{array}{l}-0.549 \\
(0.097)\end{array}$ & $\begin{array}{l}-0.513 \\
(0.045)\end{array}$ & $\begin{array}{l}-0.402 \\
(0.126)\end{array}$ \\
\hline Proposed price & $\begin{array}{c}0.022 \\
(0.024)\end{array}$ & $\begin{array}{c}0.002 \\
(0.025)\end{array}$ & $\begin{array}{c}0.037 \\
(0.032)\end{array}$ & $\begin{array}{l}-0.032 \\
(0.038)\end{array}$ & $\begin{array}{c}0.016 \\
(0.017)\end{array}$ & $\begin{array}{c}0.119 \\
(0.054)\end{array}$ \\
\hline Proposed price $\times \mathrm{TI}_{0}$ & $\begin{array}{c}0.139 \\
(0.052)\end{array}$ & $\begin{array}{c}0.117 \\
(0.044)\end{array}$ & $\begin{array}{c}0.135 \\
(0.043)\end{array}$ & $\begin{array}{c}0.084 \\
(0.067)\end{array}$ & $\begin{array}{c}0.031 \\
(0.026)\end{array}$ & $\begin{array}{c}0.098 \\
(0.169)\end{array}$ \\
\hline Flooring & $\begin{array}{l}-0.081 \\
(0.061)\end{array}$ & $\begin{array}{l}-0.047 \\
(0.065)\end{array}$ & & & & \\
\hline Flooring $\times \mathrm{TI}_{0}$ & $\begin{array}{c}0.001 \\
(0.076)\end{array}$ & $\begin{array}{c}0.003 \\
(0.072)\end{array}$ & & & & \\
\hline City effects & yes & yes & yes & yes & yes & yes \\
\hline Quarter effects & yes & yes & yes & yes & yes & yes \\
\hline \multicolumn{7}{|c|}{ Panel B. Fraction of evaders } \\
\hline Overall & $\begin{array}{c}0.554 \\
(0.036)\end{array}$ & $\begin{array}{c}0.586 \\
(0.037)\end{array}$ & $\begin{array}{c}0.606 \\
(0.040)\end{array}$ & $\begin{array}{c}0.443 \\
(0.054)\end{array}$ & $\begin{array}{c}0.641 \\
(0.048)\end{array}$ & $\begin{array}{c}0.622 \\
(0.070)\end{array}$ \\
\hline Market R & $\begin{array}{c}0.08 \\
(0.058)\end{array}$ & $\begin{array}{c}0.107 \\
(0.065)\end{array}$ & $\begin{array}{c}0.081 \\
(0.069)\end{array}$ & $\begin{array}{c}0.040 \\
(0.097)\end{array}$ & $\begin{array}{c}0.177 \\
(0.100)\end{array}$ & $\begin{array}{c}0.284 \\
(0.145)\end{array}$ \\
\hline Market U & $\begin{array}{c}0.711 \\
(0.043)\end{array}$ & $\begin{array}{c}0.710 \\
(0.043)\end{array}$ & $\begin{array}{c}0.753 \\
(0.047)\end{array}$ & $\begin{array}{c}0.638 \\
(0.069)\end{array}$ & $\begin{array}{c}0.742 \\
(0.053)\end{array}$ & $\begin{array}{c}0.726 \\
(0.082)\end{array}$ \\
\hline$\Delta$ Markets & $\begin{array}{c}0.630 \\
(0.074) \\
\end{array}$ & $\begin{array}{c}0.603 \\
(0.080) \\
\end{array}$ & $\begin{array}{c}0.672 \\
(0.084) \\
\end{array}$ & $\begin{array}{c}0.597 \\
(0.129) \\
\end{array}$ & $\begin{array}{c}0.565 \\
(0.115) \\
\end{array}$ & $\begin{array}{c}0.442 \\
(0.172) \\
\end{array}$ \\
\hline $\mathrm{N}$ & 658 & 665 & 518 & 205 & 266 & 104 \\
\hline
\end{tabular}

Note: Panel A reports results from linear regression of the acceptance rate on the invoice treatment indicator and different sets of control variables. The proposed price is standardized to zero mean and unit variance. Clustered standard errors at the advertisement level reported in parentheses. Panel B reports fraction of evaders calculated from predicted values of the regression. Standard errors of the intention to evade and their difference are obtained from bootstrapping with 499 replications. 
the experiment. Columns (5) and (6) report the results from advertisements for painting four rooms or installing parquet floor in one room (see Appendix A.2. The coefficient on the interaction between market and the invoice treatment is in both jobs about 15 ppts smaller than in the main experiment (panel A). Panel B shows that this is primarily due to differences in the behavior of businesses operating on the regulated market. It has to be considered that each advertisement in the extension was posted in four cities only and the results using the samples are based on few observations. The fraction of evaders in the unregulated market is very similar across the different types of jobs. Although at a slightly lower level, the results confirm the finding that market differences are substantial.

\section{Businesses' reaction to consumers' signals}

\subsection{The effect of asking for price discounts}

The baseline and invoice treatments with discount $\left(\mathrm{TB}_{10}, \mathrm{TI}_{10}, \mathrm{~TB}_{20}\right.$ and $\left.\mathrm{TI}_{20}\right)$ allow us to study if the fraction of evaders increases in response to consumers asking for a price discount (hypothesis 2). Demanding a lower price may signal consumers' willingness to collaborate in exchange for a lower price. Figure 4 shows that compared to the no discount condition asking for a discount decreases the willingness to accept our offer in all treatments. However, as expected, the willingness to accept the invoice treatment decreases more strongly than the willingness to accept the baseline treatment, at least when we demand for a discount of $20 \%$. This implies that the fraction of evaders increases.

We pool the observations from the six baseline and invoice treatments and run regressions to investigate if we can confirm the descriptive result when we control for city and quarter effects as well as differences between markets, job types, and initial price proposals (columns 1 and 2, Table 7, panel A). The coefficients show the absolute changes in acceptance rate which are not very informative. Therefore, we use the regression results to calculate the relative changes in job acceptance by treatment (see Panel B). In line with expectations, we observe a lower decrease of the acceptance rates in the baseline treatment. Panel $\mathrm{C}$ reports the fraction of evaders without and with discount predicted from regressions. In addition, it displays the changes of this fraction relative to the case without discount. We find no significant increase when consumers ask for a discount of $10 \%$. We find a significant increase of 8 ppts for a discount request of $20 \%$ (at the $10 \%$ level); the fraction of evaders increases to $64 \%$ of all contractors willing to do the job.

In columns (3) and (4) of Table 7, we report the results by marketplace. In the regulated market, the fraction of evaders increases when we ask businesses for a discount albeit the increase is statistically insignificant. In the unregulated market, no clear cut pattern is observed. This may be explained by the high fraction of informal businesses. 
Figure 4: Acceptance rates and fraction of evaders with price discounts

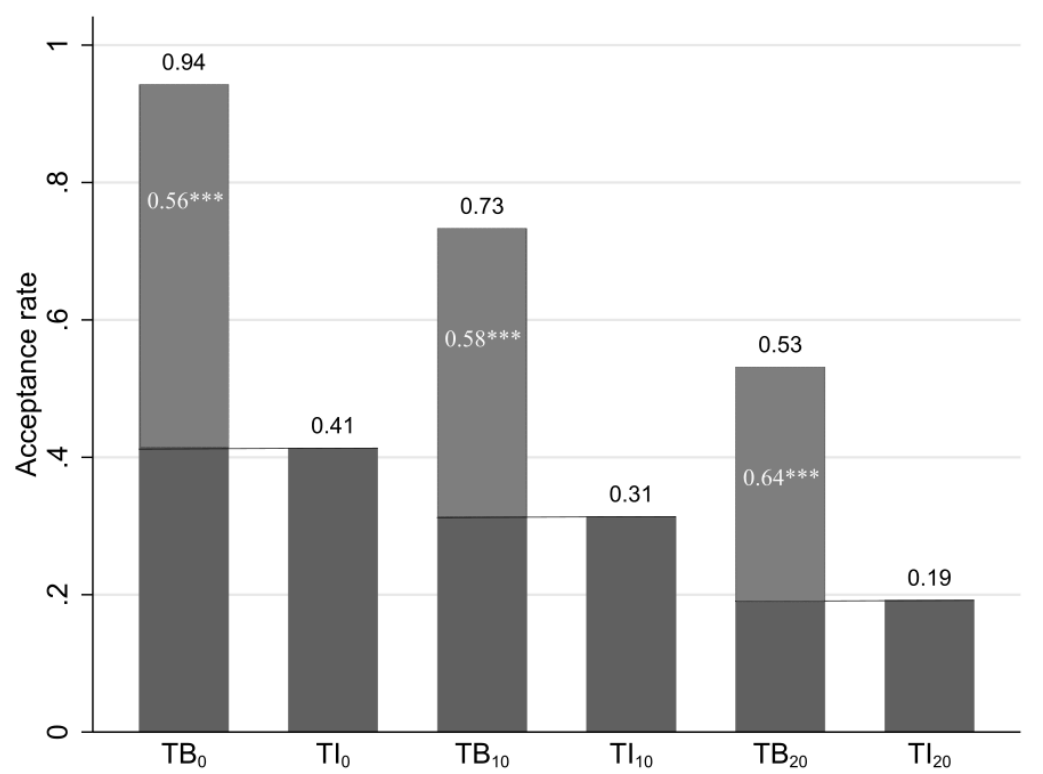

Note: The bars show the proportion of applicants accepting our conditions in the baseline treatment and invoice treatments with no discount $\mathrm{TB}_{0}(\mathrm{~N}=365), \mathrm{TI}_{0}(\mathrm{~N}=358)$, with a $10 \%$ discount $\mathrm{TB}_{10}(\mathrm{~N}=367), \mathrm{TI}_{10}(\mathrm{~N}=373)$ and with a $20 \%$ discount $\mathrm{TB}_{20}(\mathrm{~N}=367)$, $\mathrm{TI}_{20}(\mathrm{~N}=365)$. The fraction of evaders $\gamma_{0}, \gamma_{10}$, and $\gamma_{20}$ are calculated as the difference between acceptance rates in the baseline and invoice treatment divided by the acceptance rate of the baseline treatment. Standard errors are obtained by bootstrapping with 499 replications. p-values are marked as ${ }^{*} \mathrm{p}<0.1,{ }^{* *} \mathrm{p}<0.05,{ }^{* * *} \mathrm{p}<0.01$. 
Table 7: Regression results with price discounts

\begin{tabular}{|c|c|c|c|c|}
\hline & \multicolumn{2}{|c|}{ Overall } & \multirow{2}{*}{$\frac{\text { Market R }}{(3)}$} & \multirow{2}{*}{$\frac{\text { Market U }}{(4)}$} \\
\hline & $(1)$ & $(2)$ & & \\
\hline \multicolumn{5}{|l|}{ Panel A. Coefficients from regression } \\
\hline Invoice treatment $\mathrm{TI}_{0}$ & $\begin{array}{l}-0.528 \\
(0.024)\end{array}$ & $\begin{array}{l}-0.515 \\
(0.023)\end{array}$ & $\begin{array}{c}-0.000 \\
(0.042)\end{array}$ & $\begin{array}{l}-0.703 \\
(0.031)\end{array}$ \\
\hline Baseline Discount $10 \% \mathrm{~TB}_{10}$ & $\begin{array}{l}-0.208 \\
(0.026)\end{array}$ & $\begin{array}{l}-0.207 \\
(0.025)\end{array}$ & $\begin{array}{l}-0.226 \\
(0.064)\end{array}$ & $\begin{array}{l}-0.203 \\
(0.027)\end{array}$ \\
\hline Discount $10 \% \times$ Invoice treatment $\mathrm{TI}_{10}$ & $\begin{array}{c}0.107 \\
(0.037)\end{array}$ & $\begin{array}{c}0.100 \\
(0.035)\end{array}$ & $\begin{array}{l}-0.069 \\
(0.081)\end{array}$ & $\begin{array}{l}-0.169 \\
(0.042)\end{array}$ \\
\hline Baseline Discount $20 \% \mathrm{~TB}_{20}$ & $\begin{array}{l}-0.412 \\
(0.032)\end{array}$ & $\begin{array}{l}-0.410 \\
(0.031)\end{array}$ & $\begin{array}{l}-0.480 \\
(0.067)\end{array}$ & $\begin{array}{l}-0.389 \\
(0.034)\end{array}$ \\
\hline Discount $20 \% \times$ Invoice treatment $\mathrm{TI}_{20}$ & $\begin{array}{c}0.189 \\
(0.042)\end{array}$ & $\begin{array}{c}0.186 \\
(0.041)\end{array}$ & $\begin{array}{l}-0.024 \\
(0.097)\end{array}$ & $\begin{array}{c}0.268 \\
(0.047)\end{array}$ \\
\hline Market U & no & yes & - & - \\
\hline Market $\mathrm{U} \times \mathrm{TI}$ & no & yes & - & - \\
\hline Proposed price & no & yes & yes & yes \\
\hline Proposed price $\times \mathrm{TI}$ & no & yes & yes & yes \\
\hline Flooring & no & yes & yes & yes \\
\hline Flooring $\times \mathrm{TI}$ & no & yes & yes & yes \\
\hline City effects & yes & yes & yes & yes \\
\hline Quarter effects & yes & yes & yes & yes \\
\hline \multicolumn{5}{|l|}{ Panel B. Relative changes of acceptance rates } \\
\hline Baseline with $10 \%$ discount $\left(\mathrm{TB}_{0}\right.$ vs. $\left.\mathrm{TB}_{10}\right)$ & -0.221 & -0.222 & -0.250 & -0.213 \\
\hline Invoice with $10 \%$ discount $\left(\mathrm{TI}_{0}\right.$ vs. $\left.\mathrm{TI}_{10}\right)$ & -0.243 & -0.246 & -0.331 & -0.133 \\
\hline Baseline with $20 \%$ discount $\left(\mathrm{TB}_{0}\right.$ vs. $\left.\mathrm{TB}_{20}\right)$ & -0.437 & -0.437 & -0.531 & -0.408 \\
\hline Invoice with $20 \%$ discount $\left(\mathrm{TI}_{0}\right.$ vs. $\left.\mathrm{TI}_{20}\right)$ & -0.538 & -0.535 & -0.567 & -0.479 \\
\hline \multicolumn{5}{|l|}{ Panel C. Fraction of evaders } \\
\hline No discount $\gamma_{0}$ & $\begin{array}{c}0.561 \\
(0.038)\end{array}$ & $\begin{array}{c}0.563 \\
(0.036)\end{array}$ & $\begin{array}{c}0.017 \\
(0.052)\end{array}$ & $\begin{array}{c}0.735 \\
(0.043)\end{array}$ \\
\hline $10 \%$ discount $\gamma_{10}$ & $\begin{array}{c}0.573 \\
(0.042)\end{array}$ & $\begin{array}{c}0.576 \\
(0.052)\end{array}$ & $\begin{array}{c}0.123 \\
(0.187)\end{array}$ & $\begin{array}{c}0.708 \\
(0.052)\end{array}$ \\
\hline $20 \%$ discount $\gamma_{20}$ & $\begin{array}{c}0.639 \\
(0.052)\end{array}$ & $\begin{array}{c}0.639 \\
(0.052)\end{array}$ & $\begin{array}{c}0.092 \\
(0.187)\end{array}$ & $\begin{array}{c}0.767 \\
(0.052)\end{array}$ \\
\hline$\Delta \gamma_{10}-\gamma_{0}$ & $\begin{array}{c}0.012 \\
(0.043)\end{array}$ & $\begin{array}{c}0.017 \\
(0.037)\end{array}$ & $\begin{array}{c}0.107 \\
(0.110)\end{array}$ & $\begin{array}{l}-0.027 \\
(0.041)\end{array}$ \\
\hline$\Delta \gamma_{20}-\gamma_{0}$ & $\begin{array}{c}0.079 \\
(0.051) \\
\end{array}$ & $\begin{array}{c}0.076 \\
(0.048) \\
\end{array}$ & $\begin{array}{c}0.075 \\
(0.194) \\
\end{array}$ & $\begin{array}{c}0.032 \\
(0.047) \\
\end{array}$ \\
\hline $\mathrm{N}$ & 2195 & 2195 & 539 & 1656 \\
\hline
\end{tabular}

Note: Panel A reports results from linear regression of the acceptance rate on treatment dummies and different sets of control variables. The proposed price is standardized to zero mean and unit variance. Clustered standard errors at the advertisement level reported in parentheses. Panel B reports the relative changes on the acceptance rates of the discount treatments relative to the treatments without discount request. Panel $\mathrm{C}$ reports the fraction of evaders calculated from predicted values of the regression and the changes of the fraction of evaders caused by consumer induced price pressure. Standard errors of the fractions of evaders and relative changes are obtained from bootstrapping with 499 replications. 
Our hypothesis that asking for a price discount causes some formal businesses to switch from declaration to evasion is confirmed. However, the reaction is rather weak and only significant if the price discount is as high as the VAT. The signal does not seem to be very strong as consumers can negotiate about the price without having the intention to evade.

\subsection{The effect of asking for cash prices}

As another test of hypothesis 2, we study how businesses' willingness to evade changes when consumers ask for a "cash price". The treatment differs from the ones studied above in that we receive answers to two questions ("Does the price include an invoice? How much would it be if I pay cash?"). The analysis is based on 283 subjects. We exclude $10 \%$ of treated subjects which do not reply to the treatment and $6 \%$ that ask for a call. ${ }^{22}$

To estimate the fraction that deviates from their intention when consumers ask for a "cash price", we first need to classify them based on their initial intention. Panel A of Table 8 shows that $41 \%$ proposed their price assuming that the transaction will be declared, $59 \%$ assumed that the transaction will be evaded. The fractions are remarkably close to the ones reported in Figure 2 (44\% and 56\%). The same applies to the findings by marketplace. Hence, the results reported in Section 4.1 provide a robust estimate of the fractions that intend to evade and declare.

Panel B of Table 8 shows that $22 \%$ of the contractors that initially intended to declare propose a "cash price" when consumers ask for it, thereby revealing their willingness to collaboratively evade taxes. This means that at least every second contractor $(22 \%$ of $41 \%$, i.e., $54 \%$ ) that approached the consumer with the intention to declare is willing to evade if consumers ask for a "cash" price. The fraction of evaders increases to $81 \%$.

In the regulated market, $40 \%$ of those that initially intended to declare (38\% of $94 \%$ ) are willing to switch to evasion. Although the number of those approaching the consumer with the intention to evade is close to zero, a total fraction of $43 \%$ is willing to offer the service without an invoice if consumers strongly signal their willingness to collaborate. The effect is even stronger in the unregulated market, where $64 \%$ (18\% of $28 \%$ ) of initial declarers are willing to switch to evasion. The fraction of evaders increases to $90 \%$. The finding that businesses react to a lesser extent to consumers' signal in the regulated market suggests that contractors still worry about the platform becoming an informed third party.

The treatment also reveals how many contractors who initially proposed a cash price are willing to propose an invoice price. Panel C of Table 8 shows that $24 \%$ of all contractors are willing to switch from evasion to declaration. Summing up those who proposed a price

\footnotetext{
${ }^{22}$ It is difficult to assess to what extent the exclusion of these subjects implies a bias of the results. A bias could arise, e.g., if subjects do not respond because they are not willing to give a "cash price". It has to be considered that also in the baseline treatment $T B_{0}$ in which we do not amend contractors' offers $6 \%$ do not respond to our treatment (see Section 4.1).
} 
Table 8: Reactions to $T Q$ and composition of businesses

\begin{tabular}{|c|c|c|c|}
\hline & Total & Market R & Market U \\
\hline \multicolumn{4}{|l|}{ Panel A. Initial intentions } \\
\hline Fraction of declarers $\left(1-\gamma_{0}\right)$ & $\begin{array}{c}0.406 \\
(0.035)\end{array}$ & $\begin{array}{c}0.943 \\
(0.053)\end{array}$ & $\begin{array}{c}0.283 \\
(0.032)\end{array}$ \\
\hline Fraction of evaders $\gamma_{0}$ & $\begin{array}{c}0.594 \\
(0.040)\end{array}$ & $\begin{array}{c}0.057 \\
(0.032)\end{array}$ & $\begin{array}{c}0.717 \\
(0.044)\end{array}$ \\
\hline \multicolumn{4}{|c|}{ Panel B. Switching from declaration to evasion } \\
\hline From declare to evade & $\begin{array}{c}0.219 \\
(0.027)\end{array}$ & $\begin{array}{c}0.377 \\
(0.071)\end{array}$ & $\begin{array}{c}0.183 \\
(0.027)\end{array}$ \\
\hline Fraction of evaders & $\begin{array}{c}0.813 \\
(0.043)\end{array}$ & $\begin{array}{c}0.434 \\
(0.072)\end{array}$ & $\begin{array}{c}0.900 \\
(0.045)\end{array}$ \\
\hline \multicolumn{4}{|c|}{ Panel C. Switching from evasion to declaration } \\
\hline From evade to declare & $\begin{array}{c}0.244 \\
(0.029)\end{array}$ & $\begin{array}{c}0.057 \\
(0.032)\end{array}$ & $\begin{array}{c}0.287 \\
(0.034)\end{array}$ \\
\hline Fraction of declarers & $\begin{array}{c}0.650 \\
(0.041)\end{array}$ & $\begin{array}{c}1.000 \\
(0.045)\end{array}$ & $\begin{array}{c}0.570 \\
(0.042)\end{array}$ \\
\hline \multicolumn{4}{|c|}{ Panel D. Composition of businesses } \\
\hline Only declare (formal) $\omega_{F}$ & $\begin{array}{c}0.187 \\
(0.026)\end{array}$ & $\begin{array}{c}0.566 \\
(0.074)\end{array}$ & $\begin{array}{c}0.100 \\
(0.021)\end{array}$ \\
\hline Declare and evade (formal) $\gamma_{F}$ & $\begin{array}{c}0.463 \\
(0.037)\end{array}$ & $\begin{array}{c}0.434 \\
(0.072)\end{array}$ & $\begin{array}{c}0.470 \\
(0.040)\end{array}$ \\
\hline Only evade (informal) $\gamma_{I}$ & $\begin{array}{c}0.350 \\
(0.033)\end{array}$ & $\begin{array}{c}0.000 \\
(-)\end{array}$ & $\begin{array}{c}0.430 \\
(0.038)\end{array}$ \\
\hline $\mathrm{N}$ & 283 & 53 & 230 \\
\hline
\end{tabular}

Note: Panel A reports businesses' initial intention inferred from the answer to the two questions. In Panel B, we report how many of those that intended to declare are willing to switch to evasion in reaction to our treatment. In Panel $\mathrm{C}$, we report how many of those that intended to evade are willing to switch to declaration in reaction to our treatment. In Panel D, we classify contractors into businesses that only declare, businesses that evade and declare and businesses that only evade. The group of declarers includes those who send a cash price including an invoice. Standard errors are obtained from bootstrapping with 499 replications. 
including an invoice and those that are willing to switch from evasion to declaration shows that in total $65 \%$ of contractors are willing to declare. The result provides suggestive evidence on businesses' evasion motives. The $41 \%$ (24\% of $59 \%$ ) that agree to issue an invoice when consumers ask for it seem to approach consumers with the intention to evade due to financial motives. The remaining $59 \%$ seem to be informal businesses. Since they are not willing to switch to declaration even if they can request any price, we conclude that they are not able to do so. In line with expectations, we find that any business operating on the regulated market is willing to declare if they can request any price. In the unregulated market, $40 \%$ ( $28 \%$ of $71 \%$ ) seem to be driven by financial motives, whereas the $60 \%$ that are not willing to change seem to be informal businesses. The results are remarkably close to the ones obtained from refusing responses, see Section 4.1.

In Panel D of Table 8, we classify the contractors as formal businesses that always declare $\omega_{F}$, formal businesses that are flexible $\gamma_{F}$ and informal businesses $\gamma_{I}$ (see, Section 2 ). First, $19 \%$ of all contractors are only willing to do the job if an invoice is issued, even if consumers clearly signal the willingness to collaborate. Second, $46 \%$ of contractors are flexible, i.e., they declare or evade depending on the price that is paid by the consumer. Third, $35 \%$ of all contractors are not at all willing (or able) to issue an invoice. We take this number as an approximation of the share of informal businesses on online markets for renovation services. A differentiation by market shows that this fraction is zero in the regulated market and amounts to $43 \%$ on the unregulated market.

\section{The estimation of evasion rents}

When businesses and consumers agree to collaborate, the tax enforcement capacity of the government decreases dramatically. Acknowledging that deterrence may be ineffective in fostering tax compliance in business-to-consumer transactions, several countries have introduced tax subsidies to reduce the financial benefit of evasion (Williams and Nadin, 2014). The effectiveness of this instrument is likely to be negatively correlated with evasion rents. Hence, from a policy perspective it is highly relevant to learn about the magnitude of the price discount that consumers receive in case of collaboration. We expect that businesses propose an evasion rent that is at least as high as the tax subsidy (hypothesis 3) 23 We test this hypothesis based on variation between and within businesses.

The between business variation comes from the difference between average proposed prices (predicted from regressions controlling for city and quarter effects) of those who accept the baseline and invoice treatments. The average proposed price of those who accept the baseline treatment $\bar{P}_{T B}$ is the average of the proposed prices of declarers $\bar{P}_{D}$

\footnotetext{
${ }^{23}$ While it would be interesting to study how businesses and consumers share the evasion rent, our analysis does not allow us to quantify the savings of businesses.
} 
and evaders $\bar{P}_{E}$ weighted with the share of the group: $\bar{P}_{T B}=\bar{P}_{D} \cdot \omega+\bar{P}_{E} \cdot \gamma$. The price of those accepting the baseline treatment $\bar{P}_{T B}$ is shown in Table 9 , Panel A, column (1). We assume that the average proposed price of declarers $\overline{\mathrm{P}}_{\mathrm{D}}$ equals the average price proposals of contractors accepting the invoice treatment $\overline{\mathrm{P}}_{\mathrm{TI}}$ (column 2). Assuming equal shares and average prices of declarers across the baseline and invoice treatment, we solve for the average proposed price of evaders $\bar{P}_{E}$ (column 3). The relative difference between $\bar{P}_{E}$ and $\overline{\mathrm{P}}_{\mathrm{D}}$ yields the evasion rent which is presented in column (4) ${ }^{24}$

Consumers save on average about one quarter of the declaration price if they choose a contractor that intends to evade. The evasion rent is the same with regard to both types of job. To assess if the evasion rent is significantly different from zero and from the tax subsidy of $20 \%$ of the labor costs, we obtain the empirical bootstrap distribution of the rent and the differences to zero and 0.2 (499 replications, sampling with replacement). As shown in columns (5) and (6), the evasion rent is significantly different from zero (painting at $1 \%$-level, flooring at $10 \%$-level) but not from the tax subsidy.

Table 9: Evasion rents

\begin{tabular}{|c|c|c|c|c|c|c|c|}
\hline & & $(1)$ & $(2)$ & $(3)$ & $(4)$ & $(5)$ & $(6)$ \\
\hline & $\mathrm{N}$ & $\overline{\mathrm{P}}_{\mathrm{TB}}$ & $\begin{array}{l}\overline{\mathrm{P}}_{\mathrm{TI}} \\
\overline{\mathrm{P}}_{\mathrm{D}}\end{array}$ & $\overline{\mathrm{P}}_{\mathrm{E}}$ & $\begin{array}{c}\text { Evasion } \\
\text { rent } \epsilon\end{array}$ & $\begin{array}{c}\mathrm{p} \text {-values } \\
\Delta \text { to } 0\end{array}$ & $\begin{array}{l}\mathrm{p} \text {-values } \\
\Delta \text { to } 0.2\end{array}$ \\
\hline \multicolumn{8}{|c|}{ Panel A: Proposed prices and declaration intentions from $T B_{0}$ and $T I_{0}$} \\
\hline Painting & 347 & 257.9 & 306.0 & 227.3 & 0.26 & 0.001 & 0.234 \\
\hline Floor installing & 145 & 524.3 & 586.6 & 447.6 & 0.24 & 0.056 & 0.402 \\
\hline \multicolumn{8}{|c|}{ Panel B: Cash and invoice prices holding business constant } \\
\hline \multicolumn{8}{|c|}{ Overall } \\
\hline Painting & 87 & - & 348.4 & 250.7 & 0.28 & 0.000 & 0.003 \\
\hline Floor installing & 43 & - & 591.4 & 443.8 & 0.25 & 0.000 & 0.017 \\
\hline \multicolumn{8}{|c|}{ Only those with reference invoice } \\
\hline Painting & 37 & - & 356.2 & 292.6 & 0.18 & 0.000 & 0.158 \\
\hline Floor installing & 25 & - & 582.1 & 470.2 & 0.19 & 0.000 & 0.357 \\
\hline \multicolumn{8}{|c|}{ Only those with reference cash } \\
\hline Painting & 50 & - & 342.6 & 219.6 & 0.36 & 0.000 & 0.000 \\
\hline Floor installing & 18 & - & 604.4 & 407.2 & 0.33 & 0.000 & 0.000 \\
\hline
\end{tabular}

Note: Prices are reported in Euro. In panel A, average prices in column (1), (2) are calculated from contractors that accepted the conditions. They are obtained from regressions in which we control for city and quarter effects. Column (3) calculated from (1) and (2) as described in text. In Panel B, column (2) refers to the invoice price, (3) to the cash price. In both panels, the evasion rent reported in column (4) obtained as $[(2)-(3)] /(2)$. The p-values have been obtained from an empirical bootstrap distribution of the evasion rent and its difference zero and the tax subsidy of $20 \%$ (499 replications, sampling with replacement). ${ }^{24}$ We present evasion rents by job because price offers differ substantially between the two jobs. Also
from consumer perspective, it is natural to compare prices within services and not between services. 
To calculate the evasion rent from within variation, we use the responses from contractors who reported an invoice and a cash price in treatment $T Q$. Results are presented in Table 9, panel B. On average, consumers of painting services can save $28 \%$ of the invoice price if they choose the cash price from a contractor that is willing to provide both prices. For flooring services the average savings amount to $25 \%$. The results are remarkably similar to the ones reported in panel A. They suggest that differences across businesses do not influence the magnitude of the average evasion rent.

The treatment allows us to provide additional evidence on the evasion rent. Figure 5 illustrates the cumulative distribution of evasion rents for both jobs. Consumers can save from $10 \%$ to over $60 \%$ of the invoice price when they agree to collaborate. The sample is almost equally split in contractors who give a price discount above $20 \%$ and contractors who give a price discount below $20 \%$. The magnitude of the discount is influenced by the initial intention, as shown in the lower part of Panel B of Table 9. We find that those who approached us with the intention to declare are willing to give a discount of $18-19 \%$ which is equal to the VAT in Germany. The difference between cash and invoice price of who approached us with the intention to evade is about one third. The result is the same for both jobs. This is evidence for deterrence pricing, i.e., businesses proposing high invoice prices to deter consumers from insisting on an invoice.

Figure 5: Distribution of evasion rents holding contractor constant

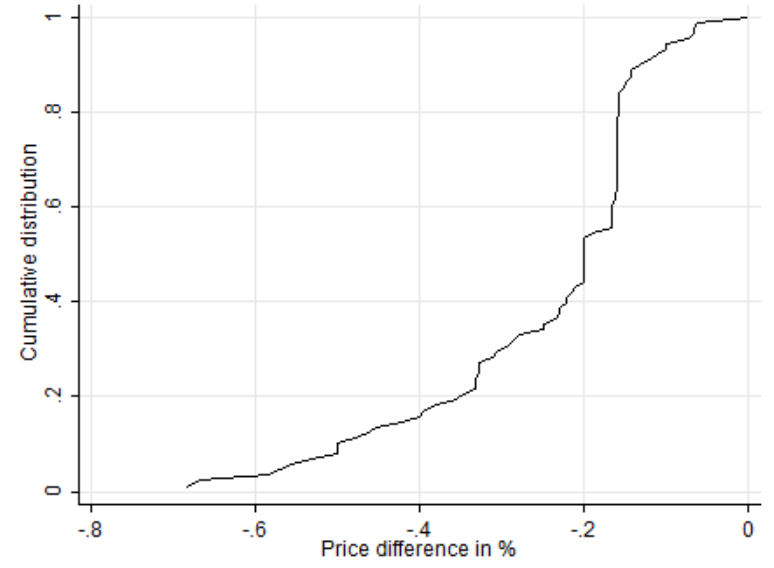

(a) Painting

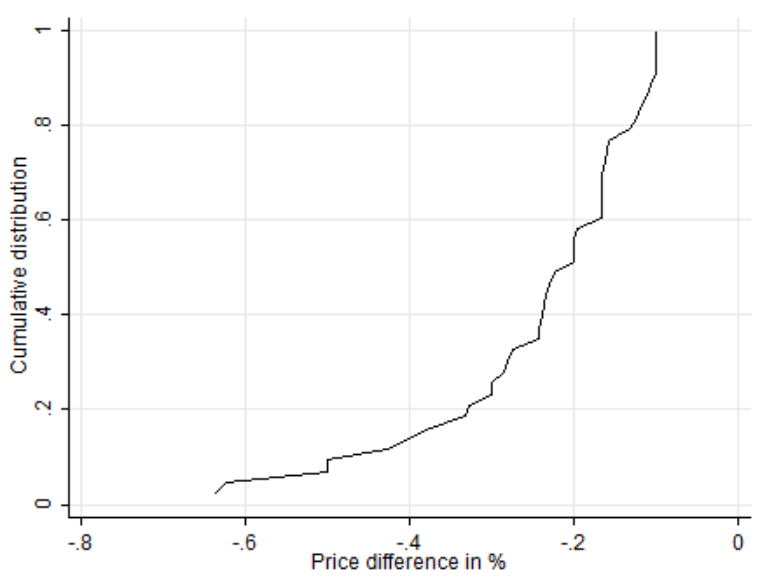

(b) Floor installation

Note: The lines show the cumulative density distribution of the relative difference between invoice and cash price reported in TQ. Painting $\mathrm{N}=87$, Flooring $\mathrm{N}=42$. 


\section{Discussion}

Our study quantifies the fraction of businesses approaching consumers with the intention to evade and the evasion rents that collaborating consumers receive. We obtain evidence by exposing businesses to contract conditions that they can accept or reject and by interacting with them in a more qualitative way. The two different approaches yield remarkably similar results. We conclude that our findings have high internal validity.

The experiment relies on advertisements of small-scale home repair and remodeling jobs. The main results are very similar for the two types of job considered in the experiment (painting/floor installation) and also hold when we demand different volumes of these services. We expect that the results would be similar for other comparable smallscale jobs, e.g., car repair or gardening.

The advantage of running the experiment on online platforms is that we receive a broad range of offers, i.e., from registered companies as well as from contractors offering a "private" service. Since informal businesses are by definition not registered, it is difficult to get in contact with them. Online markets allow us to overcome this problem. A possible limitation of advertising the jobs on online markets is that two types of suppliers are not captured. First, officially registered tradesmen that do not use the internet for selling services are disregarded. We expect that they would behave in a similar manner as contractors approaching us through the regulated market. Second, transactions initiated via social connections (e.g., through acquaintances) are not captured. We expect that contractors hired through social connections are at least as likely to evade as contractors approaching us through the unregulated market. In addition, since the two neglected groups are likely to present two opposing extremes, we expect that considering them would not substantially change the average experience of consumers.

The finding that the fraction of evaders is large in the unregulated market and close to zero in the regulated market suggests that the possibility of tracking illegal transactions strongly decreases the willingness to collaborate. It is likely that the willingness to evade would be higher if the negotiations would take place in personal conversations. Hence, our estimates would present an underestimate of the fraction of evaders.

\section{Conclusion}

Tax evasion is estimated to be particularly high when businesses sell products or services to consumers (e.g., Kleven et al., 2011; Naritomi, 2016; Pomeranz, 2015). However, only a few, mostly theoretical, studies explore the collaboration between businesses and consumers (Boadway et al., 2002; Chang and Lai, 2004). Our research makes a contribution to this literature in a new direction. By running a field experiment in a naturally 
occurring market, we are the first to estimate the fraction of businesses that approach consumers with the intention to evade taxes. We investigate how this fraction varies with the regulation of the market on which the transaction takes place and consumer signals about their willingness to collude. In addition, we calculate evasion rents.

The experiment shows that $56 \%$ of contractors approach consumers with the intention to evade. In line with expectations, we find stark differences by market. In the regulated market, the fraction of evaders is close to zero. In contrast, in the unregulated market almost three out of four contractors intend to evade. Price pressure has only a weak effect on the fraction of evaders. It increases to $64 \%$ when we ask for a $20 \%$ discount. However, the fraction of evaders increases to $80 \%$ when consumers' signal their willingness to collude by asking for a "cash price". Consumers can save $25 \%$ on average if they choose a business that intends to evade the transaction.

Our results have important policy implications. Although the experimental design does not allow us to infer the causal effect of market design, the results show that restricting access to formal businesses and keeping track of businesses' credentials seems to have a strong impact on the intention of businesses. In the regulated market, at least in written conversations contractors only agree to evade taxes if consumers explicitly signal their intention to collaborate. In addition, businesses' reaction to consumers' signal is still lower in the regulated than in the unregulated market.

Governments that use or aim to use tax subsidies to combat tax evasion should expect that consumers' evasion rents might at least match this subsidy. In addition, since $59 \%$ of the evaders seem to be informal businesses, governments should consider which features of the legislation influence the decision to be informal. It is likely that the registration processes are too complex for contractors who offer small scale and relatively cheap services, e.g., as a side hustle. Reducing the bureaucratic and monetary costs of registration may motivate some businesses to register. 


\section{References}

Abeler, J., A. Becker, and A. Falk (2014). Representative evidence on lying costs. Journal of Public Economics 113, 96-104.

Abraham, M., K. Lorek, F. Richter, and M. Wrede (2017). Collusive Tax Evasion and Social Norms. International Tax and Public Finance 24(2), 179-197.

Allingham, M. G. and A. Sandmo (1972). Income Tax Evasion: A Theoretical Analysis. Journal of Public Economics 1(3), 323 - 338.

Balafoutas, L., A. Beck, R. Kerschbamer, and M. Sutter (2015). The Hidden Costs of Tax Evasion: Collaborative Tax Evasion in Markets for Expert Services. Journal of Public Economics 129, 14-25.

Becker, G. S. (1968). Crime and Punishment: An Economic Approach. The Journal of Political Economy 76(2), 169-217.

Boadway, R., N. Marceau, and S. Mongrain (2002). Joint Tax Evasion. Canadian Journal of Economics/Revue canadienne d'économique 35(3), 417-435.

Chang, J.-J. and C.-C. Lai (2004). Collaborative Tax Evasion and Social Norms: Why Deterrence Does Not Work. Oxford Economic Papers 56(2), 344368.

European Commission (2014). Special Eurobarometer 402: Undeclared Work in the European Union. DOI: 10.2767/37041.

Fedeli, S. and F. Forte (1999). Joint Income-Tax and VAT-Chain Evasion. European Journal of Political Economy 15(3), 391-415.

Feld, L. P. and C. Larsen (2012). Undeclared Work, Deterrence, and Social norms - The Case of Germany. University Press of Southern Denmark.

Fischbacher, U. and F. Föllmi-Heusi (2013). Lies in disguise - an experimental study on cheating. Journal of the European Economic Association 11, 525-547.

Flory, J. A., A. Leibbrandt, and J. A. List (2015). Do Competitive Workplaces Deter Female Workers? A Large-Scale Natural Field Experiment on Job Entry Decisions. Review of Economic Studies 82(1), 122-155.

Fooken, J., T. Hemmelgarn, and B. Herrmann (2015). Improving VAT Compliance Random Awards for Tax Compliance. Taxation Papers 51, Directorate General Taxation and Customs Union, European Commission. 
Gokalp, O. N., S.-H. Lee, and M. W. Peng (2017). Competition and Corporate Tax Evasion: An Institution-Based View. Journal of World Business 52(2), 258-269.

Hallsworth, M. (2014). The Use of Field Experiments to Increase Tax Compliance. Oxford Review of Economic Policy 30(4), 658-679.

Harrison, G. W. and J. A. List (2004). Field Experiments. Journal of Economic Literature 42(4), 1009-1055.

Immordino, G. and F. F. Russo (2017). Cashless Payments and Tax Evasion. European Journal of Political Economy, available online.

Initiative D21 (2015). D21-Digital-Index 2015, Die Gesellschaft in der digitalen Transformation. Eine Studie der Initiative D21, durchgefhrt von TNS Infratest.

Initiative D21 (2016). D21-Digital-Index 2016, Jhrliches Lagebild zur Digitalen Gesellschaft. Eine Studie der Initiative D21, durchgefhrt von Kantar TNS.

Kerschbamer, R., D. Neururer, and M. Sutter (2016). Insurance Coverage of Customers Induces Dishonesty of Sellers in Markets for Credence Goods. Proceedings of the $\mathrm{Na}$ tional Academy of Sciences 113(27), 7454-7458.

Kleven, H. J. (2014). How Can Scandinavians Tax So Much? Journal of Economic Perspectives 28(4), 77-98.

Kleven, H. J., M. B. Knudsen, C. T. Kreiner, S. Pedersen, and E. Saez (2011). Unwilling or Unable to Cheat? Evidence from a Tax Audit Experiment in Denmark. Econometrica $79(3), 651-692$.

Kleven, H. J., C. T. Kreiner, and E. Saez (2016). Why Can Modern Governments Tax So Much? An Agency Model of Firms as Fiscal Intermediaries. Economica 83(330), 219-246.

Le Maux, B., S. Necker, and Y. Rocaboy (2018). Cheat or Perish? A Theory of Scientific Customs.

Leibbrandt, A. and J. A. List (2014). Do Women Avoid Salary Negotiations? Evidence from a Large-Scale Natural Field Experiment. Management Science 61(9), 1-9.

Mas, A. and A. Pallais (2017). Valuing Alternative Work Arrangements. American Economic Review 107(12), 3722-59.

Naritomi, J. (2016). Consumers as Tax Auditors. Working Paper - The London School of Economics and Political Science. 
Pomeranz, D. (2015). No Taxation Without Information: Deterrence and SelfEnforcement in the Value Added Tax. The American Economic Review 105(8), 25392569.

Slemrod, J. (2007). Cheating Ourselves: The Economics of Tax Evasion. Journal of Economic Perspectives 21(1), 25-48.

Slemrod, J. and C. Weber (2012). Evidence of the Invisible: Toward a Credibility Revolution in the Empirical Analysis of Tax Evasion and the Informal Economy. International Tax and Public Finance 19(1), 25-53.

Strand, J. (2005). Tax Distortions, Household Production, and Black-Market Work. European Journal of Political Economy 21(4), 851-871.

Williams, C. C. and S. Nadin (2014). Tackling Undeclared Work in the European Union. Technical report, Cesifo Forum 2/2012.

Yaniv, G. (1993). Collaborated Employee-Employer Tax Evasion. National Insurance Institute, Administration of Research and Planning.

Zentralverband des Deutschen Handwerks (2014). Digitalisierung der Geschftsprozesse im Handwerk, Ergebnisse einer Umfrage unter Handwerksbetrieben im ersten Quartal 2014. ZDH; Juni 2014.

Zentralverband des Deutschen Handwerks (2016). ZDH Sonderumfrage Digitaler Wandel, Ergebnisse einer Umfrage unter Handwerksbetrieben im 3. Quartal 2016. SU 2/16; $\mathrm{ZDH}$. 


\section{A.1 Appendix - For Online Publication}

\section{A.2 Extension}

To understand if our results apply also to other volumes of the service, we extend the experiment and post two additional advertisements. We search for contractors who paint four rooms (80sqm) and contractors who install parquet floor in one room (20sqm). In the extension, we focus on the question of how many contractors are willing to accept our conditions at their proposed price and send contractors interested in these jobs randomly the baseline treatement $\mathrm{TB}_{0}$ or the invoice treatment $\mathrm{TI}_{0}(2 \times 2$ design $)$. The advertisements for painting four rooms and installing parquet floors in one room were each posted in four cities between August and October 2017. We received 370 job applications in the extension of the experiment. Summary statistics can be found in Table A.1 and A.2.

Table A.1: Number and average prices of offers by market and advertisement

\begin{tabular}{lcccccc}
\hline \hline & \multicolumn{2}{c}{ Total } & \multicolumn{2}{c}{ Market R } & \multicolumn{2}{c}{ Market U } \\
\cline { 2 - 7 } & $\mathrm{N}$ & Mean price & $\mathrm{N}$ & Mean price & $\mathrm{N}$ & Mean price \\
\hline \multicolumn{2}{l}{ Extension: } & Painting four/Floor & installation & one room(s) & & \\
\hline Total & 370 & 453.4 & 70 & 530.5 & 300 & 435.4 \\
Painting & 266 & 525.2 & 46 & 618.8 & 220 & 505.7 \\
Flooring & 104 & 269.7 & 24 & 361.3 & 80 & 242.2 \\
\hline
\end{tabular}

Table A.2: Balancing of pre-treatment characteristics

\begin{tabular}{|c|c|c|c|c|c|c|c|c|c|}
\hline & \multirow{2}{*}{$\mathrm{N}$} & \multicolumn{4}{|c|}{$\begin{array}{l}\text { Proposed } \\
\text { price }\end{array}$} & \multicolumn{2}{|c|}{$\begin{array}{c}\text { Application } \\
\text { via market } U\end{array}$} & \multicolumn{2}{|c|}{$\begin{array}{l}\text { Application } \\
\text { flooring job }\end{array}$} \\
\hline & & Mean & SD & Min & Max & Mean & $\mathrm{SD}$ & Mean & SD \\
\hline \multicolumn{10}{|c|}{ Extension: One/four room advertisement } \\
\hline $\mathrm{TB}_{0}$ & 180 & 441.4 & 270.1 & 100 & 1600 & 0.83 & 0.38 & 0.27 & 0.47 \\
\hline $\mathrm{TI}_{0}$ & 190 & 464.8 & 336.5 & 80 & 2700 & 0.80 & 0.39 & 0.29 & 0.45 \\
\hline
\end{tabular}




\section{A.3 Wording in English}

\section{Advertisement painting}

I am looking for a contractor to paint two rooms, in total 40 (80) sqm. There are no slopes and the walls are approx. $2.5 \mathrm{~m}$ high. Ceilings do not have to be painted. The rooms will be empty. Wallpapering is unnecessary. The walls are currently white with woodchip wallpaper. White paint (brand $\mathrm{x}$ ) and covering material will be provided. It is not possible to view the site before. Please send me your price proposal (excl. material). Thank you!

\section{Advertisement parquet flooring}

I am looking for a contractor to install parquet floor in two rooms, in total 40 (20) sqm. The room is rectangular. The parquet floor should be installed using the floating method. I will provide the flooring parquet (brand $\mathrm{x}$ ) as well as skirting boards. It is not possible to view the site before. Please send me your proposed price (excl. material). Thank you!

\section{Treatment $\mathrm{TB}_{0}$ : Baseline, no discount}

Thanks for your offer of $X €$. The job should be done within the next four weeks. The price of $X €$ would be okay for me. If you agree, please get back to me and let me know when you could do the job. I have received several offers and will decide in the next few days. Thank you!

\section{Treatment $\mathbf{T I}_{0}$ : Invoice, no discount}

Thanks for your offer of $X €$. The job should be done within the next four weeks. The price of $X €$ would be okay for me. I need an invoice, I would like to deduct the costs from taxes. If you agree, please get back to me and let me know when you could do the job. I have received several offers and will decide in the next few days. Thank you!

\section{Treatment $\mathrm{TB}_{10}$ : Baseline, $10 \%$ discount}

Thanks for your offer of $X €$. The job should be done within the next four weeks. The price of $(1-0.1) \cdot X €$ would be okay for me. If you agree, please get back to me and let me know when you could do the job. I have received several offers and will decide in the next few days. Thank you! 


\section{Treatment $\mathrm{TI}_{10}$ : Invoice, $10 \%$ discount}

Thanks for your offer of $X €$. The job should be done within the next four weeks. The price of $(1-0.1) \cdot X €$ would be okay for me. I need an invoice, I would like to deduct the costs from taxes. If you agree, please get back to me and let me know when you could do the job. I have received several offers and will decide in the next few days. Thank you!

\section{Treatment $\mathrm{TB}_{20}$ : Baseline, 20\% discount}

Thanks for your offer of $X €$. The job should be done within the next four weeks. The price of $(1-0.2) \cdot X €$ would be okay for me. If you agree, please get back to me and let me know when you could do the job. I have received several offers and will decide in the next few days. Thank you!

\section{Treatment $\mathrm{TI}_{20}$ : Invoice, $20 \%$ discount}

Thanks for your offer of $X €$. The job should be done within the next four weeks. The price of $(1-0.2) \cdot X €$ would be okay for me. I need an invoice, I would like to deduct the costs from taxes. If you agree, please get back to me and let me know when you could do the job. I have received several offers and will decide in the next few days. Thank you!

\section{Treatment TQ: Qualitative}

Thanks for your offer. Does it include an invoice? How much would it cost if I pay in cash?

Additional interactions in case questions not clearly answered:

1. In case of ambiguous price(s): "So $X$ includes an invoice? How much would it cost if I pay in cash?"

2. When the contractor reports that price includes an invoice but no cash price was given in the first answer: "And how much would it cost if I pay in cash?"

3. When the contractor reports that price is cash and no invoice price was given in the first answer: "And how much would it cost including an invoice?"

\section{Rejection}

Thank you again for your offer. Unfortunately, I have to inform you that we have chosen someone else. 


\section{A.4 Map of cities}

Figure A.1: Map of cities

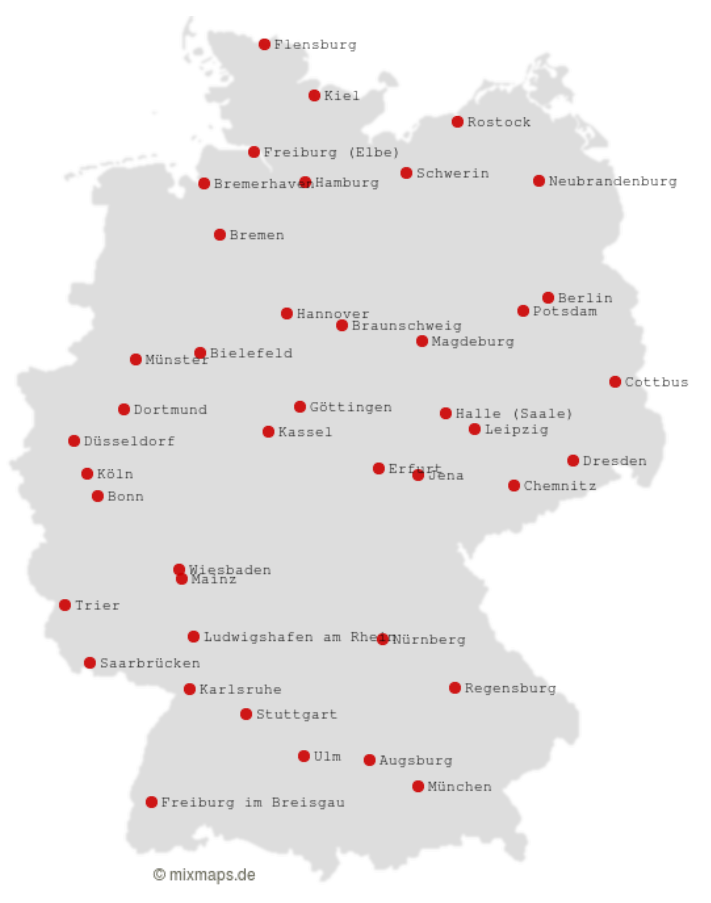

(a) Painting

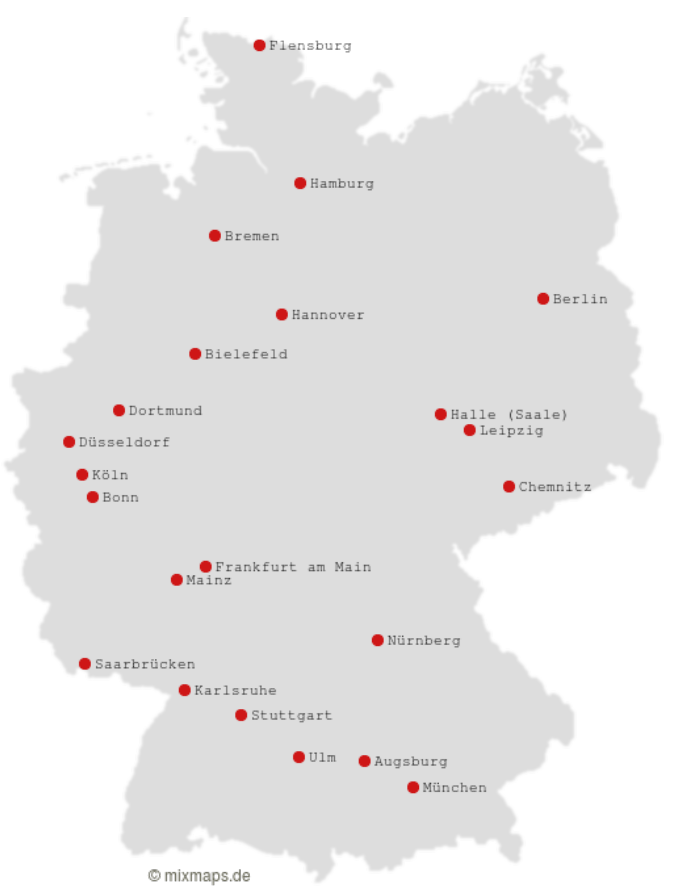

(b) Floor installation

Note: The advertisement for painting services were posted in 42 cities and those for parquet installation services in 22 of these cities. 


\section{A.5 Discussion of identification strategy}

\section{A.5.1 Identification of the fraction of evaders}

The fraction of evaders $\gamma$ is defined as the share of those who intend to evade among all who accept the job. In probability notation it is the conditional probability of being an evader given that the job is accepted, $P(\gamma \mid a c c)$. Using Bayes rule, the fraction of evaders is equal to the conditional probability shown in equation (1)

$$
\gamma=P(\gamma \mid a c c)=\frac{P(a c c \mid \gamma) \cdot P(\gamma)}{P(a c c)}
$$

In the following we show that the fraction of evaders can be identified from the difference of acceptance rates of the baseline and invoice treatment based on two assumptions.

In the baseline treatment $\mathrm{TB}_{0}$, we do not mention whether we need an invoice or not. We assume that businesses accept the treatment independent of their declaration intention. The probability that a business accepts the job given the contract conditions in the baseline treatment is the sum of the probability of acceptance given the business is a declarer $\omega$ and the probability of acceptance given the business is an evader $\gamma$ weighted with the probability of being that type of business:

$$
P\left(a c c \mid \mathrm{TB}_{0}\right)=P(a c c)=P(a c c \mid \omega) \cdot P(\omega)+P(a c c \mid \gamma) \cdot P(\gamma) .
$$

In the invoice treatment $\mathrm{TI}_{0}$, we stress that an invoice (I) is needed to deduct the service costs from the tax bill. The probability that a business accepts the job given the contract conditions in the invoice treatment can again be written as the sum of the probabilities of accepting the job when the business is a declarer or a evader and willing to issue an invoice weighted with the probability of being that type of business:

$$
P\left(a c c \mid \mathrm{TI}_{0}\right)=P(a c c \mid I)=P(a c c \mid \omega, I) \cdot P(\omega, I)+P(a c c \mid \gamma, I) \cdot P(\gamma, I) .
$$

However, making the issuing of an invoice a condition for the job, this treatment should only be accepted by those who intend to declare the transaction.

Assumption 1 (A1) (Compliance).

$$
P(a c c \mid \gamma, I)=0
$$

We assume the probability of acceptance given the business is an evader and receives the invoice treatment is zero. In other words, all contractors who accept the invoice treatment will comply with declaration. This assumption is highly plausible since we 
explicitly state that we will deduct the costs from taxes. As described in Section 4, we thereby signal that public authorities will learn about the transaction if the contractor agrees to do the service. It is very unlikely that contractors will issue an invoice and refuse to declare if the transaction actually takes place. By issuing an invoice they generate a paper trail of the executed service, which would serve as a proof against them in case of a tax audit. Under assumption 1, the probability that a business accepts the job given the contract conditions in the invoice treatment reduces to

$$
P\left(a c c \mid \mathrm{TI}_{0}\right) \stackrel{A 1}{=} P(a c c \mid \omega, I) \cdot P(\omega, I)
$$

Furthermore, we assume consistent behavior of those who intend to declare across both treatments

Assumption 2 (A2) (Consistency).

$$
P(\operatorname{acc} \mid \omega) \cdot P(\omega)=P(\operatorname{acc} \mid \omega, I) \cdot P(\omega, I)
$$

The share of those who accept the job with the intention to declare in the baseline treatment is equal to the share of those who accept the job with the intention to declare in the invoice treatment. In other words, the intention is independent of the type of treatment. This assumption is plausible. When applying for the job the contractors send a price proposal without knowing our contract conditions. When sending a price offer, contractors should have decided whether or not the price involves an invoice.

Given that both assumptions hold the fraction of evaders $\gamma$ is identified from the differences of acceptance rates of the two treatments divided by the acceptance rate of the baseline treatment,

$$
\gamma=P(\gamma \mid a c c)=\frac{P\left(a c c \mid \mathrm{TB}_{0}\right)-P\left(a c c \mid \mathrm{TI}_{0}\right)}{P\left(a c c \mid \mathrm{TB}_{0}\right)} \stackrel{A 1, A 2}{=} \frac{P(a c c \mid \gamma) \cdot P(\gamma)}{P(a c c)}
$$

\section{A.5.2 Violations of assumptions}

Violation of assumption 1:

When assumption 1 does not hold, some of the evaders would accept the invoice treatment, $P(a c c \mid \gamma, I)>0$. In that case, we overestimate the group of those with the intention to declare and underestimate the fraction of evaders.

$\rightarrow$ Our results would present a lower-bound estimate

Violation of assumption 2: 
There is the possibility that some contractors agree to issue an invoice if the consumer asks for it although they had in mind not to do so. This group will evade in the baseline treatment and agree to declaration in the invoice treatment. Hence, $P(\operatorname{acc} \mid \omega) \cdot P(\omega)<P(\operatorname{acc} \mid \omega, I) \cdot P(\omega, I)$. A violation of assumption 2 again leads to an underestimation of the true fraction of evaders.

$\rightarrow$ Our results would present a lower-bound estimate 